\title{
Mapping of Spectral Density Functions Using Heteronuclear NMR Relaxation Measurements
}

\author{
JEFFREY W. PENG $* \dagger$ AND GERHARD WAGNER $* \ddagger$ \\ * Department of Biological Chemistry and Molecular Pharmacology, Harvard Medical School, 240 \\ Longwood Avenue, Boston, Massachusetts 02115; and $†$ Biophysics Research Division, \\ University of Michigan, 2200 Bonisteel Boulevard, Ann Arbor, Michigan 48109
}

Received June 9, 1991; revised October 22, 1991

\begin{abstract}
A method is proposed for direct mapping of spectral density functions of the rotational motions of $\mathrm{H}-\mathrm{X}$ bond vectors, such as ${ }^{1} \mathrm{H}-{ }^{15} \mathrm{~N}$, by measuring a set of NMR relaxation parameters. The well known and frequently measured relaxation parameters $T_{1}$ and $T_{2}$ probe the spectral density function $J(\omega)$ at five frequencies: $0, \omega_{\mathrm{N}}, \omega_{\mathrm{H}}, \omega_{\mathrm{H}}-\omega_{\mathrm{N}}$, and $\omega_{\mathrm{H}}$ $+\omega_{N}$. In this study, the longitudinal relaxation time $T_{1}\left(\mathrm{~N}_{z}\right)$, the transverse relaxation times of in-phase coherence, $T_{2}\left(N_{x, y}\right)$, and of antiphase coherence, $T_{2}\left(2 \mathrm{H}_{z} \mathrm{~N}_{x, y}\right)$, the relaxation time of longitudinal two-spin order, $T_{1}\left(2 \mathrm{H}_{z} \mathrm{~N}_{z}\right)$, and the heteronuclear crossrelaxation rate $\sigma_{\mathrm{HN}}$ are measured for the heteronucleus $N$. These five relaxation parameters sample the spectral density function $J(\omega)$ at the same five points where each measurement samples a subset of these frequencies with different weights. The five measurements permit an analytical calculation of $J(\omega)$ at these five frequencies. Since longitudinal proton relaxation plays a role in these relaxation parameters, a sixth measurement is necessary to determine this relaxation time. The theory and experimental techniques for measuring these relaxation parameters are discussed. Preliminary results of these techniques as applied to the ${ }^{15} \mathrm{~N}$-enriched protein eglin $\mathrm{c}$ are described. The proposed approach has the advantage that it does not rely on any a priori model assumptions about the shape of $J(\omega)$; i.e., measurement of $J(\omega)$ and interpretation can be separated. (ब 1992 Academic Press, Inc.
\end{abstract}

Heteronuclear NMR relaxation times probe the motions of $\mathrm{XH}$ bonds (e.g., ${ }^{13} \mathrm{C}$ ${ }^{1} \mathrm{H},{ }^{15} \mathrm{~N}-{ }^{1} \mathrm{H}$ ) in proteins through their dependence on the spectral density functions belonging to these bonds. The form of the spectral density functions, $J(\omega)$, are determined by the fluctuations of the $\mathrm{XH}$ bonds with respect to the external magnetic field. Thus, the problem of characterizing the dynamics of the $\mathrm{XH}$ bond vectors reduces to the problem of characterizing the spectral densities. Current relaxation studies of proteins typically measure several parameters (e.g., $T_{1}, T_{2}$, and NOE) for the backbone ${ }^{15} \mathrm{~N}$ and ${ }^{13} \mathrm{C}$ nuclei $(1-5)$. While the measured relaxation rates are a function of $J(\omega)$ at specific frequencies, they cannot determine what these values are (vide infra). Thus, the spectral densities cannot be characterized experimentally using these measurements alone, and functional forms for $J(\omega)$ prescribed by theoretical models of motion must be used for further analysis. Most commonly used are the "wobbling-in-a-cone" model [see, for example, Woessner et al. (6), Kinoshita et al. (7), Richarz et al. (8) or the so-called "model-free approach" of Lipari and Szabo (9)]. Woessner's "wobbling-in-

‡ To whom correspondence should be addressed. 
a-cone" model dominated the relaxation time research until 1982, while the Lipari and Szabo model has had this function for the last decade. Both approaches make an a priori assumption about a simple functional form of $J(\omega)$, depending on some parameters, such as an overall rotational correlation time, $\tau_{c}$, and order parameter, $S^{2}$, a cone opening angle, and so on. The experimentally measured relaxation times are then used to fit the parameters of the model. Recently, more extensive sets of relaxation parameters have become available due to ${ }^{15} \mathrm{~N}$ and ${ }^{13} \mathrm{C}$ labeling and because of the resolution in heteronuclear $2 \mathrm{D}$ experiments that have become available for measuring relaxation parameters $(1,3)$. The newly available data have shown that the simple Lipari and Szabo approach (9) cannot completely describe the relaxation data in proteins (4). Therefore, the model can be extended to fit the experimental data with more parameters (4) or alternative routes must be sought.

Here, we describe a more direct approach in which the spectral density functions are evaluated at select frequencies independent of a motional model. This is achieved by measuring a sufficient number of heteronuclear relaxation parameters, which include not only $T_{1}$ values and NOEs, but additional parameters, such as the relaxation rate of longitudinal two-spin order and separate transverse relaxation rates of in-phase and antiphase coherence. The approach facilitates a better comparison with theoretical models of motion, since it is the spectral densities themselves that are being compared. In what follows, we employ the principal results of the semiclassical relaxation theory, which expresses relaxation rates in terms of the spectral density functions. The fundamental principles of the semiclassical theory are given in a number of texts $(10-$ 12 ), and detailed discussions concerning the theory of relaxation processes in terms of spectral density functions have been given in previous studies by Bain and LyndenBell (13), Werbelow and Grant (14), and Vold and Vold (15). We first highlight these results and then use them to discuss the dynamical information content of various heteronuclear NMR relaxation parameters and how they may be used to obtain explicit values of $J(\omega)$. Finally, we present results of this method as applied to a uniformly ${ }^{15} \mathrm{~N}$-enriched protein, eglin $\mathrm{c}$.

\section{THEORETICAL ASPECTS}

Principal results from the semiclassical relaxation theory. We use a nomenclature convenient for the discussion of heteronuclear ${ }^{15} \mathrm{~N}$ relaxation studies in proteins. In what follows, $\mathrm{N}$ refers to an ${ }^{15} \mathrm{~N}$ spin, and $\mathrm{H}^{\mathrm{N}}$ refers to its directly bound amide proton. All other protons are denoted $\mathrm{H}^{i}$. Relaxation parameters are designated by $R_{\mathrm{obs}}(Q)$, where "obs" refers to the type of nucleus, or nuclei, whose relaxation rates are being probed (either $\mathrm{H}, \mathrm{N}$, or both), and $Q$ refers to the spin operator(s) relevant to the relaxation process. For example, the spin-lattice relaxation rate of a ${ }^{15} \mathrm{~N}$ nucleus is denoted $R_{\mathrm{N}}\left(\mathrm{N}_{z}\right)$, and the heteronuclear cross-relaxation rate is $R_{\mathrm{N}}\left(\mathrm{H}_{z}^{\mathrm{N}} \rightarrow \mathrm{N}_{z}\right)$. Although our discussion will be in the context of ${ }^{15} \mathrm{~N}$ relaxation, the results are also applicable for the relaxation processes in other heteronuclear $\mathrm{XH}$ systems, such as directly bonded ${ }^{13} \mathrm{C}-{ }^{1} \mathrm{H}$ spin pairs.

We denote the perturbing Hamiltonian responsible for the relaxation of the spin system by $V(t)$. In general, a variety of interactions may contributc to the nct rclaxation. Accordingly, we express $V(t)$ as the sum 


$$
V(t)=\sum_{k} V_{k}(t)
$$

where each $V_{k}(t)$ can be expressed in the interaction frame (10-12) as

$$
\begin{array}{r}
V_{k}(t)=-\sqrt{\frac{10}{3}} A_{k} \sum_{q=-2}^{2} \sum_{\mu=-1}^{1}(-)^{q} \mathcal{D}_{q 0}^{(2)}\left[\Omega_{\mathrm{lab}}^{k}(t)\right]\left[\begin{array}{ccc}
1 & 1 & 2 \\
\mu & q-\mu & -q
\end{array}\right] \\
\times \exp \left[i\left(\mu \omega_{S}^{k}+(q-\mu) \omega_{T}^{k}\right) t\right] S_{\mu}^{k} T_{q-\mu}^{k} .
\end{array}
$$

Here, we have written the perturbing Hamiltonian in the spherical basis using the Wigner 3- $J$ symbols (16). The index $k$ in Eq. [1] sums over the possible interactions causing relaxation of the spin system. These may include the dipole-dipole and chemical-shift anisotropy (CSA) interactions provided the latter is described by an axially symmetric shielding tensor. To illustrate, $k$ would run from 1 to 3 in a system of three nonequivalent spins to account for the three distinct dipole-dipole interactions. If one of these spins had significant anisotropy in its chemical-shift shielding tensor, the upper limit of $k$ would then extend to $4 . A_{k}$ is a physical constant which depends on the specific nature of interaction $k$. As an example, for the dipolar interaction between the $\mathrm{N}$ and $\mathrm{H}^{\mathrm{N}}$ spins this constant is $3 \gamma_{\mathrm{H}} \gamma_{\mathrm{N}} \hbar^{2} / r_{\mathrm{NH}^{\mathrm{N}}}^{3}$, where $r_{\mathrm{NH}^{\mathrm{N}}}$ is the internuclear distance between $\mathrm{N}$ and $\mathrm{H}^{\mathrm{N}}$.

The spin degrees of freedom are contained in the $S_{\mu}^{k}$ and $T_{q^{-\mu}}^{k}$ operators, which are the spherical components of the two interacting vector operators specified by the $k$ th relaxation mechanism. For the dipole-dipole interaction, $S_{\mu}^{k}$ and $T_{q-\mu}^{k}$ are spin operators of the interacting nuclei. For the CSA interaction, we can take $T_{q-\mu}^{k}$ to be a spin operator of the nucleus with anisotropic shielding. $S_{\mu}^{k}$ then represents the components of the static external field, in which case $q$ runs only from -1 to 1 since $\mu$ is restricted to 0 . The laboratory spatial degrees of freedom are contained in the $D_{q 0}^{(2)}\left[\Omega_{\text {lab }}^{k}(t)\right]$ terms, which are elements of the Wigner rotation matrices and are proportional to the second-order spherical harmonics. The $\Omega_{\text {lab }}^{k}(t)$ symbol denotes the polar angles $\theta_{k}(t), \phi_{k}(t)$ of the symmetry axis belonging to the $k$ th interaction tensor. Thus, the $\mathcal{D}_{q 0}^{(2)}\left[\Omega_{\text {lab }}^{k}(t)\right]$ terms are simply trigonometric functions which describe the axis' orientation with respect to the laboratory magnetic field (17). For the dipoledipole interaction, this axis is the vector connecting the two nuclei in the interacting spin pair. For the CSA interaction it is the symmetry axis of the shielding tensor.

From the semiclassical relaxation theory $(10-12)$, the relaxation of spin order $\langle Q\rangle$, associated with the spin operator $Q$, is described by a first-order differential equation. In this context, "spin order" includes longitudinal and transverse magnetization (e.g., $\mathrm{N}_{z}, \mathrm{~N}_{x, y}$ ), as well as antiphase coherences, longitudinal multispin orders (e.g., $\left.2 \mathrm{H}_{z}^{\mathrm{N}} \mathrm{N}_{z}\right)$, and more general $p$-quantum coherences $(p \neq 1)$. When using the term spin order, we follow the convention used by Ernst et al. (11). If we use the form of the perturbing Hamiltonian given in Eqs. [1]-[3], we obtain for $d\langle Q\rangle / d t(10-12)$

$$
\begin{aligned}
\frac{d\langle Q\rangle}{d t} & =-\frac{5}{3} \sum_{\left(k, k^{\prime}\right)} \frac{A_{k} A_{k^{\prime}}}{\hbar^{2}} \sum_{(q=-2, \mu=-1)}^{(q=2, \mu=1)}(-)^{q} \mathbf{J}_{k k^{\prime}}\left[\mu \omega_{S}^{k}\right. \\
& \left.+(q-\mu) \omega_{T}^{k}\right]\left[\begin{array}{ccc}
1 & 1 & 2 \\
\mu & q-\mu & -q
\end{array}\right]^{2} \operatorname{Tr}\left\{\left[S_{-\mu}^{k^{\prime}} T_{\mu-q}^{k^{\prime}},\left[S_{\mu}^{k} T_{q-\mu}^{k}, Q\right]\right]\left(\sigma-\sigma_{\mathrm{eq}}\right)\right\}
\end{aligned}
$$


The traces of the products of the double commutator $\left[S_{\mu}^{k^{\prime}} T_{\mu-q}^{k^{\prime}},\left[S_{\mu}^{k} T_{q-\mu}^{k}, Q\right]\right]$ with the spin density operator, $\sigma$, represent macroscopic spin orders. These will consist of $\langle Q\rangle$ itself, and possibly other distinct spin orders. The relaxation rate of $\langle Q\rangle$ is given by its own net coefficient; the coefficients of any other spin orders are then crossrelaxation rates. Again, for the CSA interaction, the index $\mu$ is restricted to 0 , and, therefore, $q$ runs only from -1 to 1 .

From a protein dynamics perspective, the salient feature of Eq. [3] is that the relaxation rate of $\langle Q\rangle$ depends on the generalized spectral density functions, $J_{k k^{\prime}}(\omega)$. In particular, $J_{k k^{\prime}}(\omega)$ is the Fourier cosine transform (10)

$$
J_{k k^{\prime}}(\omega)=2 \int_{0}^{\infty} \cos (\omega \tau) G_{k k^{\prime}}(\tau) d \tau
$$

where $G_{k k^{\prime}}(\tau)$ is a time-correlation function given by

$$
G_{k k^{\prime}}(\tau)=\left\langle\mathscr{D}_{q 0}^{(2)^{*}}\left[\Omega_{\mathrm{lab}}^{k^{\prime}}(t+\tau)\right] \mathscr{D}_{q 0}^{(2)}\left[\Omega_{\mathrm{lab}}^{k}(t)\right]\right\rangle .
$$

When $k=k^{\prime}, G_{k k^{\prime}}(\tau)$ becomes an autocorrelation function and describes the rotational diffusion of axis $k$ alone. This case is appropriate for studying the motion of an $\mathrm{NH}^{\mathrm{N}}$ bond, when the $\mathrm{NH}^{\mathrm{N}}$ dipole-dipole interactions (and possibly the chemical-shift anisotropy of the $\left.{ }^{15} \mathrm{~N}\right)$ are considered dominant. In the case that $k \neq k^{\prime}, G_{k k^{\prime}}(\tau)$ is a cross-correlation function describing the decay of correlations between the $k$ and $k^{\prime}$ terisor axes during a time $\tau$, resulting from their respective rotational diffusions. Examples include correlations between distinct dipole-dipole vectors and between a dipole-dipole vector and a CSA symmetry axis. In both cases, one spin must be shared between the two vectors or axes (18). In what follows, we consider only those cross correlations between the $\mathrm{NH}^{\mathrm{N}}$ dipole-dipole vectors (i.e., the $\mathrm{NH}^{\mathrm{N}}$ bond vector) and their associated ${ }^{15} \mathrm{~N}$ CSA symmetry axes. It has been demonstrated that the effects of these cross correlations on the relaxation kinetics can be significant, especially for ${ }^{15} \mathrm{~N}-{ }^{1} \mathrm{H}$ spin systems in peptide bonds $(19-21)$. Therefore, the total sum over $k$ and $k^{\prime}$ in Eq. [3] should include both a sum over autocorrelations $\left(k=k^{\prime}\right)$ for all relevant dipole-dipole vectors and shielding tensor symmetry axes and a sum over cross correlations $\left(k \neq k^{\prime}\right)$ for all pairs of dipole-dipole vectors and shielding tensor symmetry axes that share a common ${ }^{15} \mathrm{~N}$ nucleus. However, anticipating the experimental section, the use of recently developed pulse schemes can effectively suppress the effects of these cross correlations $(20,21)$. To this end, we can consider only the autocorrelation terms in Eq. [3], and the fluctuations of the various vectors and symmetry axes are approximated as independent. Equation [3] also shows that the relaxation rate of $\langle Q\rangle$ actually depends on a weighted sum of $J_{k k}(\omega)$ evaluated at the transition frequencies $\left[\mu \omega_{S}^{k}+(q-\mu) \omega_{T}^{k}\right]$, of the spin system, as opposed to $J_{k k}(\omega)$ directly. Thus, a single NMR relaxation rate does not "sweep" the spectral density functions; rather, it samples them at various places along the $\omega$ axis. To summarize, the time-correlation functions of Eq. [5] contain all of the dynamical information concerning the rotational fluctuations of various internuclear vectors or tensor symmetry axes within the protein. The spectral density functions depicted in Eq. [4] are simply frequency representations of these time-correlation functions. As such, they act as spectrum analyzers by providing the frequency distributions for the fluctuations of the aforementioned vectors and 
axes. This, then, is how molecular dynamics information is stored in the relaxation rate of spin order $\langle Q\rangle$ given in Eq. [3].

Relaxation rates of spin orders in an $N I^{N}$ spin system. We now consider specific cases of $Q$ in Eq. [3], corresponding to specific Cartesian operator products (22) of an $\mathrm{NH}^{\mathrm{N}}$ spin system. For $Q=\mathrm{N}_{z}$ and $\mathrm{N}_{x, y}$ we obtain the familiar expressions for $1 / T_{1}, 1 / T_{2}$, and cross-relaxation rate applicable to a particular ${ }^{15} \mathrm{~N}$ nucleus $(10)$. These are given respectively as

$$
\begin{aligned}
& R_{\mathrm{N}}\left(N_{z}\right)=\frac{\gamma_{\mathrm{H}^{\mathrm{N}}}^{2} \gamma_{\mathrm{N}}^{2} \hbar^{2}}{4 r_{\mathrm{NH}^{\mathrm{N}}}^{6}}\left\{J\left(\omega_{\mathrm{H}^{\mathrm{N}}}-\omega_{\mathrm{N}}\right)+3 J\left(\omega_{\mathrm{N}}\right)\right. \\
& \left.+6 J\left(\omega_{\mathrm{H}^{\mathrm{N}}}+\omega_{\mathrm{N}}\right)\right\}+\frac{\Delta^{2} \omega_{\mathrm{N}}^{2}}{3} J\left(\omega_{\mathrm{N}}\right) \\
& R_{\mathrm{N}}\left(\mathrm{N}_{x, y}\right)=\frac{\gamma_{\mathrm{H}^{\mathrm{N}}}^{2} \gamma_{\mathrm{N}}^{2} \hbar^{2}}{8 r_{\mathrm{NH}^{\mathrm{N}}}^{6}}\left\{4 J(0)+J\left(\omega_{\mathrm{H}^{\mathrm{N}}}-\omega_{\mathrm{N}}\right)+3 J\left(\omega_{\mathrm{N}}\right)+6 J\left(\omega_{\mathrm{H}^{\mathrm{N}}}\right)\right. \\
& \left.+6 J\left(\omega_{\mathrm{H}^{\mathrm{N}}}+\omega_{\mathrm{N}}\right)\right\}+\frac{\Delta^{2} \omega_{\mathrm{N}}^{2}}{3}\left\{\frac{2}{3} J(0)+\frac{1}{2} \mathrm{~J}\left(\omega_{\mathrm{N}}\right)\right\} \\
& R_{\mathrm{N}}\left(\mathrm{H}_{z}^{\mathrm{N}} \rightarrow \mathrm{N}_{z}\right)=\frac{\gamma_{\mathrm{H}^{\mathrm{N}}}^{2} \gamma_{\mathrm{N}}^{2} \hbar^{2}}{4 r_{\mathrm{NH}^{\mathrm{N}}}^{6}}\left\{6 J\left(\omega_{\mathrm{H}^{\mathrm{N}}}+\omega_{\mathrm{N}}\right)-J\left(\omega_{\mathrm{H}^{\mathrm{N}}}-\omega_{\mathrm{N}}\right)\right\} .
\end{aligned}
$$

In the above expressions, the operative mechanisms of relaxation are the dipoledipole interactions between the $\mathrm{N}$ spins and their directly bound protons $\left(\mathrm{H}^{\mathrm{N}}\right.$ spins $)$, as well as the CSA interaction between the $\mathrm{N}$ spins and the external field. $J(\omega)$ is the spectral density function belonging to the autocorrelation function of a particular $\mathrm{NH}^{\mathrm{N}}$ bond. Thus, the $k$ indices are dropped from Eq. [4]; $r_{\mathrm{NH}^{\mathrm{N}}}$ is the internuclear distance between the $\mathrm{N}$ and $\mathrm{H}^{\mathrm{N}}$, and $\Delta$ is the chemical-shift anisotropy of the $\mathrm{N}$ spin. Note that the presumed axial symmetry of the ${ }^{15} \mathrm{~N}$ shielding tensor conveniently allows the same $J(\omega)$ to be used for the dipolar and CSA contributions (17). The steadystate heteronuclear NOE is related to the $\mathrm{NH}^{\mathrm{N}}$ cross-relaxation rate, $R_{\mathrm{N}}\left(\mathrm{H}_{z}^{N} \rightarrow \mathrm{N}_{z}\right)$, and $R_{\mathrm{N}}\left(\mathrm{N}_{z}\right)$ through the familiar relation $(10)$

$$
\mathrm{NOE}=1+\frac{\gamma_{\mathrm{H}}}{\gamma_{\mathrm{N}}} \frac{R_{\mathrm{N}}\left(\mathrm{H}_{z}^{\mathrm{N}} \rightarrow \mathrm{N}_{z}\right)}{R_{\mathrm{N}}\left(\mathrm{N}_{z}\right)} .
$$

The relaxation behavior of two-spin orders is also of interest. Various aspects of two-spin-order relaxation have been investigated in the literature (23-27). Here, our focus is on the dynamical information available from these relaxation processes. The appropriate rate expressions are given directly by Eq. [3]. In particular, for $Q=$ $2 \mathrm{H}_{z}^{\mathrm{N}} \mathrm{N}_{z}$ and $2 \mathrm{H}_{z}^{\mathrm{N}} \mathrm{N}_{x, y}$, one finds

$$
\begin{aligned}
R_{\mathrm{NH}}\left(2 \mathrm{H}_{z}^{\mathrm{N}} \mathrm{N}_{z}\right)=\frac{\gamma_{\mathrm{H}^{\mathrm{N}}}^{2} \gamma_{\mathrm{N}}^{2} \hbar^{2}}{4 r_{\mathrm{NH}}^{6}}\left\{3 J\left(\omega_{\mathrm{N}}\right)+3 J\left(\omega_{\mathrm{H}^{\mathrm{N}}}\right)\right\}+\frac{\Delta^{2} \omega_{\mathrm{N}}^{2}}{3} J\left(\omega_{\mathrm{N}}\right)+\rho_{\mathrm{H}^{\mathrm{N}} \mathrm{H}^{i}} \\
R_{\mathrm{NH}}\left(2 \mathrm{H}_{z}^{\mathrm{N}} \mathrm{N}_{x, y}\right)=\frac{\gamma_{\mathrm{H}^{\mathrm{N}} \gamma_{\mathrm{N}}^{2} \hbar^{2}}^{8 r_{\mathrm{NH}}^{6}}\left\{4 J(0)+J\left(\omega_{\mathrm{H}^{\mathrm{N}}}-\omega_{\mathrm{N}}\right)\right.}{\left.+3 J\left(\omega_{\mathrm{N}}\right)+6 J\left(\omega_{\mathrm{H}^{\mathrm{N}}}+\omega_{\mathrm{N}}\right)\right\}+\frac{\Delta^{2} \omega_{\mathrm{N}}^{2}}{3}\left\{\frac{2}{3} J(0)+\frac{1}{2} J\left(\omega_{\mathrm{N}}\right)\right\}+\rho_{\mathrm{H}^{\mathrm{N}} \mathrm{H}^{i}}}
\end{aligned}
$$


where $\rho_{\mathrm{H}^{\mathrm{N}}} \mathrm{H}^{i}$ is the sum of rates

$$
\begin{aligned}
\rho_{\mathrm{H}^{N} \mathrm{H}^{i}}=\sum_{i} \frac{\gamma_{\mathrm{H}^{\mathrm{N}}}^{2} \gamma_{\mathrm{H}^{i}}^{2} \hbar^{2}}{4 r_{\mathrm{H}^{N} \mathrm{H}^{i}}^{6}}\left\{J _ { \mathrm { H } ^ { N } \mathrm { H } ^ { i } } \left(\omega_{\mathrm{H}^{\mathrm{N}}}-\right.\right. & \left.\omega_{\mathrm{H}^{i}}\right) \\
& \left.+3 J_{\mathrm{H}^{\mathrm{N}} \mathrm{H}^{i}}\left(\omega_{\mathrm{H}^{\mathrm{N}}}\right)+6 J_{\mathrm{H}^{\mathrm{N}} \mathrm{H}^{i}}\left(\omega_{\mathrm{H}^{\mathrm{N}}}+\omega_{\mathrm{H}^{i}}\right)\right\} .
\end{aligned}
$$

$R_{\mathrm{NH}}\left(2 \mathrm{H}_{z}^{\mathrm{N}} \mathrm{N}_{z}\right)$ is the relaxation rate for longitudinal two-spin order $2 \mathrm{H}_{z}^{\mathrm{N}} \mathrm{N}_{z}(28)$, and $R_{\mathrm{NH}}\left(2 \mathrm{H}_{z}^{\mathrm{N}} \mathrm{N}_{x, y}\right)$ is the corresponding rate for antiphase transverse coherence, $2 \mathrm{H}_{z}^{\mathrm{N}} \mathrm{N}_{x, y}$. The relaxation rates for pure zero- and two-quantum coherences can also be similarly obtained. The $\rho_{\mathrm{H}^{\mathrm{N}}} \mathrm{H}^{i}$ term given in Eqs. [10]-[12] is simply the net spinlatice relaxation rate of a given $\mathrm{H}^{\mathrm{N}}$ proton, due to other protons, $\mathrm{H}^{i}$. It consists of spectral density functions $J_{\mathrm{H}^{N_{H}}}(\omega)$, which describe the motions of the vectors joining various $\mathrm{H}^{\mathrm{N}}-\mathrm{H}^{i}$ proton spin pairs. They are not to be confused with $J(\omega)$, which is associated with fluctuations of a particular $\mathrm{NH}^{\mathrm{N}}$ bond vector. The presence of the $\rho_{\mathrm{H}^{*} \mathrm{~N}^{i}}$ term in Eqs. [10]-[11] reveals that $2 \mathrm{H}_{z}^{\mathrm{N}} \mathrm{N}_{z}$ and $2 \mathrm{H}_{z}^{\mathrm{N}} \mathrm{N}_{x, y}$ will be relaxed additionally by dipolar interactions between $\mathrm{H}^{\mathrm{N}}$ spin and other proton spins $\mathrm{H}^{i}$. In particular, these interactions induce $\mathrm{H}^{\mathrm{N}}$ spin flips that tend to destroy the specific correlations of the $\mathrm{H}^{\mathrm{N}}$ and $\mathrm{N}$ spin states defined by these two-spin orders. As a consequence, one expects antiphase coherence to relax faster than in-phase coherence (24$\left.27^{\prime}\right)$. Similarly, $2 \mathrm{H}_{z}^{\mathrm{N}} \mathrm{N}_{z}$ is expected to relax faster than $\mathrm{N}_{z}$. In ${ }^{15} \mathrm{~N}$-enriched proteins, the $\mathrm{H}^{\mathrm{N}}-\mathrm{H}^{i}$-relaxation will arise from dipole-dipole interactions between the amide proton and other spatially close protons such as the intraresidue $\mathrm{H} \alpha$ protons, or other anide protons bound to different ${ }^{15} \mathrm{~N}$ nuclei. An analogous case can be made for twospin magnetizations involving a ${ }^{13} \mathrm{C} \alpha$ and its directly bonded proton. The relaxation rates of zero- and two-quantum coherences would include a term analogous to $\rho_{\mathrm{H}^{\mathrm{N}} \mathrm{H}^{i}}$, which would essentially be the $\mathrm{H}^{\mathrm{N}}$ transverse relaxation rate due to the proton dipolar relaxation. Dipole-dipole interactions between the $\mathrm{N}$ and $\mathrm{H}^{i}$ spins are ignored in the $R_{\mathrm{NH}}\left(2 \mathrm{H}_{z}^{\mathrm{N}} \mathrm{N}_{z}\right)$ and $R_{\mathrm{NH}}\left(2 \mathrm{H}_{z}^{\mathrm{N}} \mathrm{N}_{x, y}\right)$ expressions in Eq. [10] and [11], since these interactions are negligible in practice (29). This is reasonable, given that the $\mathbf{H}^{i}$ spin is not bonded to the $\mathrm{N}$ spin, and that the dipolar interaction varies with the inverse sixth power of the internuclear distance.

Quantification of the rates given in Eqs. [6]-[8], [10], and [11] assumes that the associated spin orders $Q$ relax independently and in a monoexponential fashion. However, the presence of any cross-relaxation pathways will couple the relaxation kinetics of the different spin orders $Q$, resulting in complex multiexponential decays. Consequently, it is highly desirable to suppress these cross-relaxation pathways during the relaxation experiments, in order to achieve monoexponential behavior as closely as pcssible. For example, as first shown by Solomon (30), the relaxation of nonequilibrium $\mathrm{N}_{z}$ magnetization is generally expected to be biexponential under the heteronuclear $\mathrm{NH}^{\mathrm{N}}$ dipole-dipole interaction. To help enforce a monoexponential decay, the atlached $\mathrm{H}^{\mathrm{N}}$ spins are saturated during the relaxation period (vide infra). Another example is the aforementioned dipolar-CSA cross-correlation effect, which causes cross relaxation between the one-spin and two-spin orders $Q$. This includes cross relaxation between $\mathrm{N}_{z}$ and $2 \mathrm{H}_{z}^{\mathrm{N}} \mathrm{N}_{z}$, as well as between $\mathrm{N}_{x, y}$ and $2 \mathrm{H}_{z}^{\mathrm{N}} \mathrm{N}_{x, y}$. These crossrelaxation pathways are a manifestation of the uneven relaxation rates of the two components constituting the ${ }^{15} \mathrm{~N}$ doublet (19-21). They can be suppressed using the 
methods of Boyd et al. (20) for longitudinal relaxation measurements, and Palmer et al. (2I), for transverse measurements. Finally, cross relaxation between $2 \mathrm{H}_{z}^{\mathrm{N}} \mathrm{N}_{z}$ and $2 \mathrm{H}_{z}^{i} \mathrm{~N}_{z}$ and between $2 \mathrm{H}_{z}^{\mathrm{N}} \mathrm{N}_{x, y}$ and $2 \mathrm{H}_{z}^{i} \mathrm{~N}_{x, y}$ can, in principal, occur as a result of the homonuclear proton-proton dipolar interactions. These $\mathrm{NH}^{i}$ magnetizations represent spin-state correlations between an $\mathrm{N}$ spin and a nonbonded proton spin (e.g., between an amide ${ }^{15} \mathrm{~N}$ nucleus and the intraresidue $\mathrm{C} \alpha$ proton). These spins lack the heteronuclear one-bond scalar coupling, $J_{\mathrm{NH}}$. As a result, these contributions are not refocused in the $2 \mathrm{D}$ relaxation experiments discussed below and are not detected. Moreover, since the $\mathrm{NH}^{i}$ magnetizations are initially zero (their value at thermodynamic equilibrium) in an NMR pulse sequence and remain much smaller than the $\mathrm{NH}^{\mathrm{N}}$ magnetizations throughout the experiment, their influence on the two-spin relaxation rates can be ignored here to a first approximation.

Thus far, we have discussed relaxation rates native to the laboratory-spin frame. Anticipating what follows, it is useful here to discuss relaxation rates in a rotating frame as well. Here, we refer to a spin frame that rotates at angular frequency $\omega_{R F}$, specified by a radiofrequency field applied only to the N spins. Such an RF field could be realized by a low-power spin lock. We take the RF field to have a magnitude denoted by $\omega_{1}$. For spin locking, $\omega_{1} / 2 \pi$ will typically be restricted to the kilohertz frequency range. In the rotating spin frame, the $\mathrm{N}$ spins "see" an effective magnetic field along a new axis $z^{\prime}$, tilted from the laboratory $z$ axis by an angle $\beta$ and having a magnitude of $\omega_{\mathrm{e}}$. If we denote the offset of the RF frequency $\omega_{\mathrm{RF}}$ from the $\mathrm{N}$ spin resonance frequency by $\delta$, then $\omega_{\mathrm{e}}$ is given by $\sqrt{\omega_{1}^{2}+\delta^{2}}$. In the on-resonance case, $\omega_{\mathrm{e}}$ $=\omega_{1}$ and the effective field is tilted $90^{\circ}$ from the laboratory $z$ axis. A relaxation rate equation similar to Eq. [3] can be written for the various spin orders $Q_{\rho}$ belonging to the rotating frame. This is done conveniently through an interaction representation which introduces a tilted, doubly rotating frame for the $\mathrm{N}$ spins and retains the more familiar rotating frame for the $\mathrm{H}^{\mathrm{N}}$ spins $(10,31,32)$. Since only the $\mathrm{N}$-spin operators are described relative to the tilted axes, only they will be decorated with a " $\rho$ " subscript. Here, we consider the cases of $Q_{\rho}=\mathrm{N}_{\rho z^{\prime}}$ and $2 \mathrm{H}_{z}^{\mathrm{N}} \mathrm{N}_{\rho z^{\prime}} . \mathrm{N}_{\rho z^{\prime}}$ is associated with the component of $\mathrm{N}$-spin magnetization along the effective field. For $\beta=\pi / 2, \mathrm{~N}_{\rho z}$, is equivalent to the ordinary in-phase $\mathrm{N}_{x, y}$ coherence seen in the laboratory frame. The relaxation rate of $\mathrm{N}_{\rho z}$ ' is the heteronuclear $1 / T_{1 \rho}$. Continuing with our " $R$ " nomenclature, we denote this rate as $R_{\mathrm{N}}\left(\mathrm{N}_{\rho z^{\prime}}\right)$. In terms of the spectral densities, we have

$$
\begin{aligned}
& R_{\mathrm{N}}\left(\mathrm{N}_{\rho z^{\prime}}\right)=\frac{\gamma_{\mathrm{H}^{\mathrm{N}}}^{2} \gamma_{\mathrm{N}}^{2} \hbar^{2}}{8 r_{\mathrm{NH}^{\mathrm{N}}}^{6}}\left\{4 \sin ^{2}(\beta) J\left(\omega_{\mathrm{e}}\right)\right. \\
& +2\left[\sin ^{4}\left(\frac{\beta}{2}\right) J\left(\omega_{\mathrm{H}^{\mathrm{N}}}-\omega_{\mathrm{N}}+\omega_{\mathrm{e}}\right)+\cos ^{4}\left(\frac{\beta}{2}\right) J\left(\omega_{\mathrm{H}^{\mathrm{N}}}-\omega_{\mathrm{N}}-\omega_{\mathrm{e}}\right)\right] \\
& +6\left[\sin ^{4}\left(\frac{\beta}{2}\right) J\left(\omega_{\mathrm{N}}-\omega_{\mathrm{e}}\right)+\cos ^{4}\left(\frac{\beta}{2}\right) J\left(\omega_{\mathrm{N}}+\omega_{\mathrm{e}}\right)\right] \\
& +3 \sin ^{2} \beta\left[J\left(\omega_{\mathrm{H}^{\mathrm{N}}}+\omega_{\mathrm{e}}\right)+J\left(\omega_{\mathrm{H}^{\mathrm{N}}}-\omega_{\mathrm{e}}\right)\right] \\
& \left.+12\left[\cos ^{4}\left(\frac{\beta}{2}\right) J\left(\omega_{\mathrm{H}^{\mathrm{N}}}+\omega_{\mathrm{N}}+\omega_{\mathrm{e}}\right)+\sin ^{4}\left(\frac{\beta}{2}\right) J\left(\omega_{\mathrm{H}^{\mathrm{N}}}+\omega_{\mathrm{N}}-\omega_{\mathrm{e}}\right)\right]\right\} \\
& +\frac{\Delta^{2} \omega_{\mathrm{N}}^{2}}{3}\left\{\frac{2}{3} \sin ^{2}(\beta) J\left(\omega_{\mathrm{e}}\right)+\left[\sin ^{4}\left(\frac{\beta}{2}\right) J\left(\omega_{\mathrm{N}}-\omega_{\mathrm{e}}\right)+\cos ^{4}\left(\frac{\beta}{2}\right) J\left(\omega_{\mathrm{N}}+\omega_{\mathrm{e}}\right)\right]\right\} .
\end{aligned}
$$


As seen above, the effect of the RF field is to alter the spectral density sampling frequencies from $\omega$ to $\omega \pm \omega_{\mathrm{e}}$, for $\omega=0, \omega_{\mathrm{N}}, \omega_{\mathrm{H}^{\mathrm{N}}}, \omega_{\mathrm{H}^{\mathrm{N}}}-\omega_{\mathrm{N}}$, and $\omega_{\mathrm{H}^{\mathrm{N}}}+\omega_{\mathrm{N}}$. Since the nonzero $\omega$ values are in the megahertz range, the $\omega \pm \omega_{\mathrm{e}}$ sidebands represent deviations on the order of $0.1 \%$ from $\omega$. Thus, these sidebands represent only miniscule excursions away from $\omega$, when the megahertz "resolution" afforded by $\omega_{\mathrm{N}}, \omega_{\mathrm{H}^{\mathrm{N}}}$, $\omega_{\mathrm{H}^{\mathrm{N}}}-\omega_{\mathrm{N}}$, and $\omega_{\mathrm{H}^{\mathrm{N}}}+\omega_{\mathrm{N}}$ is considered. A more in-depth discussion regarding $R_{\mathrm{N}}\left(\mathrm{N}_{\rho z^{\prime}}\right)$ is given elsewhere (33). The antiphase counterpart to $\mathrm{N}_{\rho z^{\prime}}$ is $2 \mathrm{H}_{z}^{\mathrm{N}} \mathrm{N}_{\rho z^{\prime}}$. This product operator implies that if the $\mathrm{H}^{\mathrm{N}}$ spin is parallel (antiparallel) to the static field, then $\mathrm{N}$ is parallel (antiparallel) to the effective field. In the on-resonance limit, $2 \mathrm{H}_{z}^{\mathrm{N}} \mathrm{N}_{\rho z}$, is merely the $90^{\circ}$ tilted representation of $2 \mathrm{H}_{z}^{\mathrm{N}} \mathrm{N}_{x, y}$. As with the previous two-spin orders, $2 \mathrm{H}_{z}^{\mathrm{N}} \mathrm{N}_{\rho z^{\prime}}$, will also enjoy the effects of the $\mathrm{H}^{\mathrm{N}}$ spin relaxation. Accordingly, the rate is given by

$$
\begin{aligned}
R_{\mathrm{NH}}\left(2 \mathrm{H}_{z}^{\mathrm{N}} N_{\rho z^{\prime}}\right)= & \frac{\gamma_{\mathrm{H}^{\mathrm{N}}}^{2} \gamma_{\mathrm{N}}^{2} \hbar^{2}}{8 r_{\mathrm{NH}^{\mathrm{N}}}^{6}}\left\{4 \sin ^{2}(\beta) J\left(\omega_{\mathrm{e}}\right)+\sin ^{2}(\beta) J\left(\omega_{\mathrm{H}^{\mathrm{N}}}-\omega_{\mathrm{N}}\right)\right. \\
& +6\left[\sin ^{4}\left(\frac{\beta}{2}\right) J\left(\omega_{\mathrm{N}}-\omega_{\mathrm{e}}\right)+\cos ^{4}\left(\frac{\beta}{2}\right) J\left(\omega_{\mathrm{N}}+\omega_{\mathrm{e}}\right)\right] \\
& \left.+6 \cos ^{2}(\beta) J\left(\omega_{\mathrm{H}^{\mathrm{N}}}\right)+6 \sin ^{2}(\beta) J\left(\omega_{\mathrm{H}^{\mathrm{N}}}+\omega_{\mathrm{N}}\right)\right\} \\
& +\frac{\Delta^{2} \omega_{\mathrm{N}}^{2}}{3}\left\{\frac{2}{3} \sin ^{2}(\beta) J\left(\omega_{\mathrm{e}}\right)+\left[\sin ^{4}\left(\frac{\beta}{2}\right) J\left(\omega_{\mathrm{N}}-\omega_{\mathrm{e}}\right)\right.\right. \\
& \left.\left.+\cos ^{4}\left(\frac{\beta}{2}\right) J\left(\omega_{\mathrm{N}}+\omega_{\mathrm{e}}\right)\right]\right\}+\rho_{\mathrm{H}^{N} \mathrm{H}^{i}}
\end{aligned}
$$

Equations [13] and [14] simplify considerably in the on-resonance limit when $\beta$ approaches $\pi / 2$. If we make the approximation that $J\left(\omega \pm \omega_{\mathrm{e}}\right) \approx J(\omega)$ for a given $\omega$, then $R_{\mathrm{N}}\left(\mathrm{N}_{\rho z^{\prime}}\right)$ and $R_{\mathrm{NH}}\left(2 \mathrm{H}_{z}^{\mathrm{N}} \mathrm{N}_{\rho z^{\prime}}\right)$ reduce to $R_{\mathrm{N}}\left(\mathrm{N}_{x, y}\right)$ and $R_{\mathrm{NH}}\left(2 \mathrm{H}_{z}^{\mathrm{N}} \mathrm{N}_{x, y}\right)$, respectively, in the on-resonance limit. This can be seen by comparing Eq. [7] with Eq. [13] for the case of $R_{\mathrm{N}}\left(\mathrm{N}_{\rho z^{\prime}}\right)$ and Eq. [11] with Eq. [14] for the case of $R_{\mathrm{NH}}\left(2 \mathrm{H}_{z}^{\mathrm{N}} \mathrm{N}_{\rho z^{\prime}}\right)$. This approximation requires that $J(\omega)$ vary slowly for small deviations on the order of $\omega_{\mathrm{c}}\left(\approx 10^{3} \mathrm{rad} / \mathrm{s}\right)$, the neighborhood of a specific $\omega\left(\approx 10^{6} \mathrm{rad} / \mathrm{s}\right)$. For our purposes, we need only worry about this approximation for $\omega \neq 0$. This is discussed in more detail in the following sections.

Use of the relaxation rates to calculate spectral density samplings. Collectively, the rate expressions in Eqs. [6]-[8], [10], and [11] evaluate $J(\omega)$ at five frequencies, including $0, \omega_{N}, \omega_{H^{N}}, \omega_{H^{N}}-\omega_{N}$, and $\omega_{H^{N}}+\omega_{N}$. Thus, in principle, we have available for each $\mathrm{NH}^{\mathrm{N}}$ bond vector five samplings of its individual spectral density function. The sampling properties of the relaxation rates are schematized in Fig. 1. As stated, present relaxation studies of proteins measure $R_{\mathrm{N}}\left(\mathrm{N}_{z}\right), R_{\mathrm{N}}\left(\mathrm{N}_{x, y}\right)$, and NOE values for individual backbone ${ }^{15} \mathrm{~N}$ or ${ }^{13} \mathrm{C}$ nuclei. However, these three parameters constitute only three equations for five unknowns: $J(0), J\left(\omega_{\mathrm{N}}\right), J\left(\omega_{\mathrm{H}^{\mathrm{N}}}\right), J\left(\omega_{\mathrm{H}^{\mathrm{N}}}-\omega_{\mathrm{N}}\right)$, and $J\left(\omega_{\mathrm{H}^{\mathrm{N}}}+\omega_{\mathrm{N}}\right)$. Hence, they are intrinsically incapable of determining the spectral density at any of the sampling frequencies that they introduce. In essence, by measuring only three parameters, we are missing potentially valuable information about $J(\omega)$. 


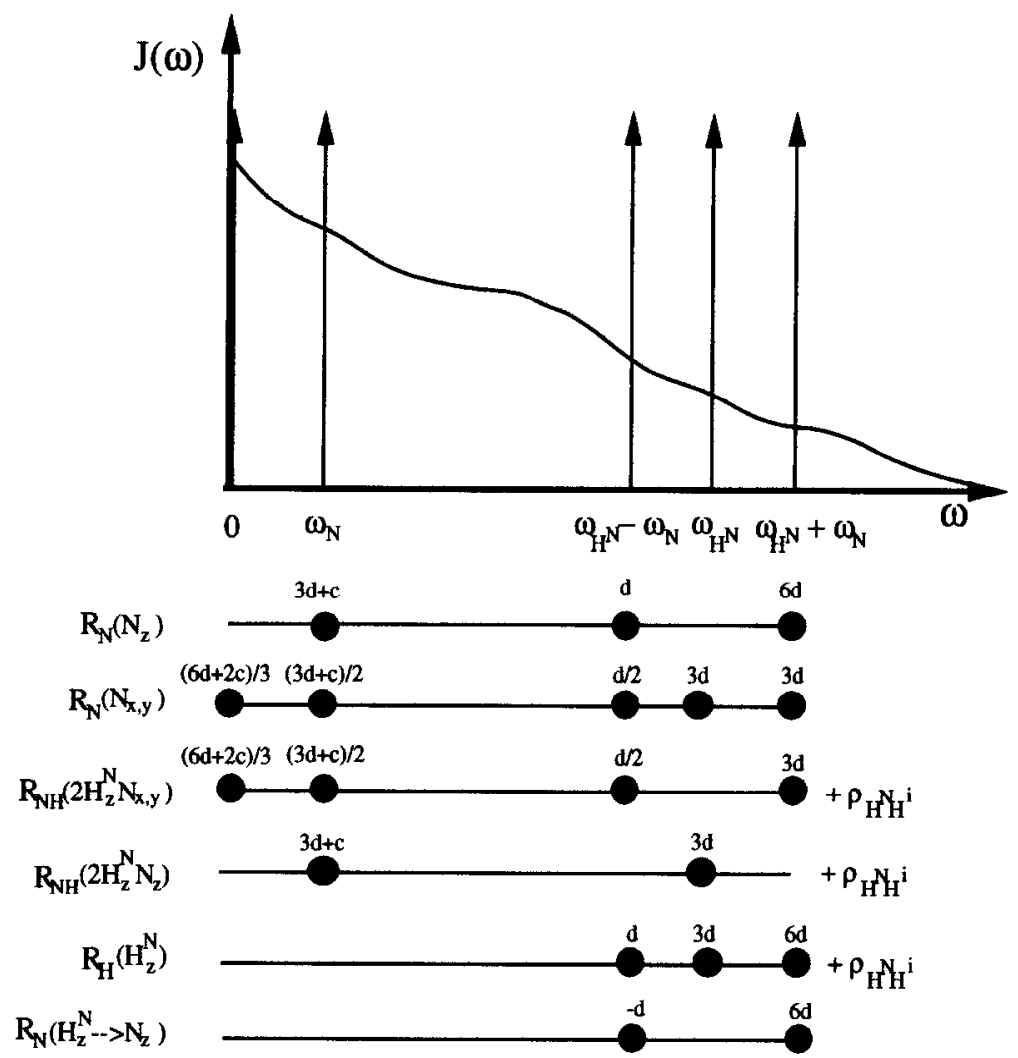

FIG. 1. Schematic representation of the samplings of $J(\omega)$ by the six relaxation parameters. These parameters include: (i) spin-lattice relaxation rate, $R_{\mathrm{N}}\left(\mathrm{N}_{z}\right)$, for the heteronucleus $\mathrm{N}$; (ii) in-phase transverse relaxation rate, $R_{\mathrm{N}}\left(\mathrm{N}_{x, y}\right)$, for the heteronucleus $\mathrm{N}$; (iii) antiphase transverse relaxation rate, $R_{\mathrm{NH}}\left(2 \mathrm{H}_{z}^{\mathrm{N}} \mathrm{N}_{x, y}\right)$; (iv) relaxation rate for longitudinal two-spin order, $R_{\mathrm{NH}}\left(2 \mathrm{H}_{z}^{\mathrm{N}} \mathrm{N}_{z}\right)$; (v) spin-lattice relaxation rate, $R_{\mathrm{H}}\left(\mathrm{H}_{z}^{\mathrm{N}}\right)$, for the $\mathrm{H}^{\mathrm{N}}$ proton; and (vi) heteronuclear cross-relaxation rate, $R_{\mathrm{N}}\left(\mathrm{H}_{z}^{\mathrm{N}} \rightarrow \mathrm{N}_{z}\right)$. The heavy circles indicate the sampling points of each relaxation rate denoted on the left. The weight for each sampling is indicated above


contains terms relating to proton-proton dipolar relaxation between a particular heteronuclear proton $\mathrm{H}^{\mathrm{N}}$ and other protons $\mathrm{H}^{i}$.

Note that the use of different field strengths will not reduce the number of unknowns. Since the spectral density samplings remain undetermined, motional models must immediately be introduced if there is to be further analysis of the relaxation data. These models make assumptions about the dynamics of the $\mathrm{NH}^{\mathrm{N}}$ bond and then introduce spectral densities composed of adjustable parameters to describe the purported motions. Thus, the very act of relating the observed relaxation times to the spectral density functions biases the dynamical analysis toward the basic assumptions of the motional model. If the model is quite complex, then one may be tempted to make exotic dynamical interpretations unjustified by the actual amount of information present in the relaxation data. In contrast, if the model is overly cautious, overinterpretation of the data is avoided, but one loses specific information about the bond dynamics. In either case, the information obtained can be misleading. 
The situation is improved if the $J(\omega)$ samplings can be determined directly by experimental means. This is possible if we exploit the information contained in the relaxation rates of both one- and two-spin relaxation measurements. For example, one could measure $R_{\mathrm{NH}}\left(2 \mathrm{H}_{z}^{\mathrm{N}} \mathrm{N}_{z}\right)$ and $R_{\mathrm{NH}}\left(2 \mathrm{H}_{z}^{\mathrm{N}} \mathrm{N}_{x, y}\right)$ values, in addition to the more customary $R_{\mathrm{N}}\left(\mathrm{N}_{z}\right), R_{\mathrm{N}}\left(\mathrm{N}_{x, y}\right)$, and NOE values. In principle, any pair of two-spin relaxation rates could be used, including the zero- and two-quantum coherence relaxation rates. Here, we focus on the use of antiphase coherence and longitudinal twospin-order relaxation rates since these are more easily measured in practice. Once the selection of two-spin relaxation parameters has been made, we can define a complete set of relaxation parameters capable of determining $J(\omega)$ at specific frequencies without recourse to a motional model. In particular, the rate expressions in Eqs. [6]-[8], [10], and [11] can be considered a system of linear algebraic equations with six unknowns: $J(0), J\left(\omega_{\mathrm{N}}\right), J\left(\omega_{\mathrm{H}^{\mathrm{N}}}\right), J\left(\omega_{\mathrm{H}^{\mathrm{N}}}-\omega_{\mathrm{N}}\right), J\left(\omega_{\mathrm{H}^{\mathrm{N}}}+\omega_{\mathrm{N}}\right)$, and $\rho_{\mathrm{H}^{N} \mathrm{H}^{i}}$. Note that for a given $\mathrm{NH}^{\mathrm{N}}$ bond, the $\rho_{\mathrm{H}^{N} \mathrm{H}^{i}}$ term can be treated as a single unknown, since it is composed of spectral densities different from $J(\omega)$. To solve for these unknowns, we must measure six relaxation parameters. It can be verified that relaxation rates in Eqs. [6]-[8], [10], and [11] are already linearly independent in the samplings. Thus, a sixth independent relaxation parameter is required. The spin-lattice relaxation rates for the $\mathrm{H}^{\mathrm{N}}$ spins can fulfill this need. For a given $\mathrm{H}^{\mathrm{N}}$ spin, this rate is

$$
R_{\mathrm{H}}\left(\mathrm{H}_{z}^{\mathrm{N}}\right)=\frac{\gamma_{\mathrm{H}^{\mathrm{N}}}^{2} \gamma_{\mathrm{N}}^{2} \hbar^{2}}{4 r_{\mathrm{NH}^{\mathrm{N}}}^{6}}\left\{J\left(\omega_{\mathrm{H}^{\mathrm{N}}}-\omega_{\mathrm{N}}\right)+3 J\left(\omega_{\mathrm{H}^{\mathrm{N}}}\right)+6 J\left(\omega_{\mathrm{H}^{\mathrm{N}}}+\omega_{\mathrm{N}}\right)\right\}+\rho_{\mathrm{H}^{N} \mathrm{H}^{i}},[15]
$$

where the first three terms account for the effects of the $\mathrm{NH}^{\mathrm{N}}$ dipolar relaxation. Thus, these six relaxation rates allow us to determine $J(\omega)$ at five frequencies. This is seen if we cast the problem in matrix algebra formalism below as

$$
\left[\begin{array}{c}
R_{\mathrm{N}}\left(\mathrm{N}_{z}\right) \\
R_{\mathrm{N}}\left(\mathrm{N}_{x, y}\right) \\
R_{\mathrm{NH}}\left(2 \mathrm{H}_{z}^{\mathrm{N}} \mathrm{N}_{x, y}\right) \\
R_{\mathrm{NH}}\left(2 \mathrm{H}_{z}^{\mathrm{N}} \mathrm{N}_{z}\right) \\
R_{\mathrm{H}}\left(\mathrm{H}_{z}^{\mathrm{N}}\right) \\
R_{\mathrm{N}}\left(\mathrm{H}_{z}^{\mathrm{N}} \rightarrow \mathrm{N}_{z}\right)
\end{array}\right]=\left[\begin{array}{cccccc}
0 & d & 3 d+c & 0 & 6 d & 0 \\
\frac{6 d+2 c}{3} & \frac{d}{2} & \frac{3 d+c}{2} & 3 d & 3 d & 0 \\
\frac{6 d+2 c}{3} & \frac{d}{2} & \frac{3 d+c}{2} & 0 & 3 d & 1 \\
0 & 0 & 3 d+c & 3 d & 0 & 1 \\
0 & d & 0 & 3 d & 6 d & 1 \\
0 & -d & 0 & 0 & 6 d & 0
\end{array}\right]\left[\begin{array}{c}
J(0) \\
J\left(\omega_{\mathrm{H}^{\mathrm{N}}}-\omega_{\mathrm{N}}\right) \\
J\left(\omega_{\mathrm{N}}\right) \\
J\left(\omega_{\mathrm{H}^{\mathrm{N}}}\right) \\
J\left(\omega_{\mathrm{H}^{\mathrm{N}}}+\omega_{\mathrm{N}}\right) \\
\rho_{\mathrm{H}^{\mathrm{N}} \mathrm{H}^{i}}
\end{array}\right]
$$

where $d=\gamma_{\mathrm{H}^{\mathrm{N}}}^{2} \gamma_{\mathrm{N}}^{2} \hbar^{2} / 4 r_{\mathrm{N} \mathrm{H}^{\mathrm{N}}}^{6}$, and $c=\Delta^{2} \omega_{\mathrm{N}}^{2} / 3$. The right-hand column vector consists of the unknown $J(\omega)$ samplings to be solved for. The left-hand vector consists of the six relaxation rates obtained from $2 \mathrm{D}$ NMR experiments. Thus, for a given $\mathrm{NH}^{\mathrm{N}}$ bond, one multiplies the vector of relaxation rates by the inverse of the matrix above to obtain the desired values of the spectral density function. In fact, it is straightforward to invert the matrix in Eq. [16] to yield the analytical solutions 


$$
\begin{aligned}
& J(0)=\frac{3}{4} \frac{1}{3 d+c}\left\{-\frac{1}{2} R_{\mathrm{N}}\left(\mathrm{N}_{z}\right)+R_{\mathrm{N}}\left(\mathrm{N}_{x, y}\right)+R_{\mathrm{NH}}\left(2 \mathrm{H}_{z}^{\mathrm{N}} \mathrm{N}_{x, y}\right)\right. \\
& \left.-\frac{1}{2} R_{\mathrm{NH}}\left(2 \mathrm{H}_{z}^{\mathrm{N}} \mathrm{N}_{z}\right)-\frac{1}{2} R_{\mathrm{H}}\left(\mathrm{H}_{z}^{\mathrm{N}}\right)\right\} \\
& J\left(\omega_{\mathrm{H}^{\mathrm{N}}}-\omega_{\mathrm{N}}\right)=\frac{1}{4} \frac{1}{d}\left\{R_{\mathrm{N}}\left(\mathrm{N}_{z}\right)-R_{\mathrm{NH}}\left(2 \mathrm{H}_{z}^{\mathrm{N}} \mathrm{N}_{z}\right)\right. \\
& \left.+R_{\mathrm{H}}\left(\mathrm{H}_{z}^{\mathrm{N}}\right)-2 R_{\mathrm{N}}\left(\mathrm{H}_{z}^{\mathrm{N}} \rightarrow \mathrm{N}_{z}\right)\right\} \\
& J\left(\omega_{\mathrm{N}}\right)=\frac{1}{2} \frac{1}{3 d+c}\left\{R_{\mathrm{N}}\left(\mathrm{N}_{z}\right)+R_{\mathrm{NH}}\left(2 \mathrm{H}_{z}^{\mathrm{N}} N_{z}\right)-R_{\mathrm{H}}\left(\mathrm{H}_{z}^{\mathrm{N}}\right)\right\} \\
& J\left(\omega_{\mathrm{H}^{\mathrm{N}}}\right)=\frac{1}{12} \frac{1}{d}\left\{-R_{\mathrm{N}}\left(\mathrm{N}_{z}\right)+2 R_{\mathrm{N}}\left(\mathrm{N}_{x, y}\right)-2 R_{\mathrm{NH}}\left(2 \mathrm{H}_{z}^{\mathrm{N}} N_{x, y}\right)\right. \\
& \left.+R_{\mathrm{NH}}\left(2 \mathrm{H}_{z}^{\mathrm{N}} \mathrm{N}_{z}\right)+R_{\mathrm{H}}\left(\mathrm{H}_{z}^{\mathrm{N}}\right)\right\} \\
& J\left(\omega_{\mathrm{H}^{\mathrm{N}}}+\omega_{\mathrm{N}}\right)=\frac{1}{24} \frac{1}{d}\left\{R_{\mathrm{N}}\left(\mathrm{N}_{z}\right)-R_{\mathrm{NH}}\left(2 \mathrm{H}_{z}^{\mathrm{N}} N_{z}\right)\right. \\
& \left.+R_{\mathrm{H}}\left(\mathrm{H}_{z}^{\mathrm{N}}\right)+2 R_{\mathrm{N}}\left(\mathrm{H}_{z}^{\mathrm{N}} \rightarrow \mathrm{N}_{z}\right)\right\} .
\end{aligned}
$$

The contribution of exclusively proton dipolar interactions to the amide proton spinlattice relaxation rate is given by

$$
\begin{aligned}
\rho_{\mathrm{H}^{\mathrm{N}} \mathrm{H}^{i}}=\left\{-\frac{1}{4} R_{\mathrm{N}}\left(\mathrm{N}_{z}\right)-\frac{1}{2} R_{\mathrm{N}}\left(\mathrm{N}_{x, y}\right)+\frac{1}{2} R_{\mathrm{NH}}\left(2 \mathrm{H}_{z}^{\mathrm{N}} \mathrm{N}_{x, y}\right)\right. \\
\left.+\frac{1}{4} R_{\mathrm{NH}}\left(2 \mathrm{H}_{z}^{\mathrm{N}} \mathrm{N}_{z}\right)+\frac{1}{4} R_{\mathrm{H}}\left(\mathrm{H}_{z}^{\mathrm{N}}\right)\right\} .
\end{aligned}
$$

For a CSA value of $\Delta=-160 \mathrm{ppm}(34)$ and an internuclear ${ }^{15} \mathrm{~N}-{ }^{1} \mathrm{H}$ bond distance of $r_{\mathrm{NH}^{\mathrm{N}}}=1.02 \AA(35)$, the constants $c$ and $d$ become $\approx 1.3 \times 10^{9}$ and $0.9 \times 10^{9}(\mathrm{rad} /$ $\mathrm{s})^{2}$, respectively.

Since the $J(\omega)$ values can now be determined at a given field strength, it becomes useful to perform identical measurements at different field strengths to expand the number of sampling points. If $n$ fields are used, then we obtain potentially $(4 n+1)$ unique detcrminations of $J(\omega)$. The result is an actual mapping of $J(\omega)$, independent of any motional models for the $\mathrm{NH}^{\mathrm{N}}$ bond vectors. Direct comparison between the experimentally determined and theoretical spectral density functions becomes feasible. The physical relevance of a given model can now be assessed on the basis of its ability to reproduce the values of $J(\omega)$ at the specified frequencies. This kind of assessment is not possible with three-parameter measurements in general, which fail to define $J(\omega)$ at even one frequency.

\section{PULSE SEQUENCES FOR MEASURING RELAXATION PARAMETERS}

Two-dimensional heteronuclear pulsc scquences for measuring the six relaxation rates are shown in Figs. 2a-2f. Some of these sequences, or similar versions have 

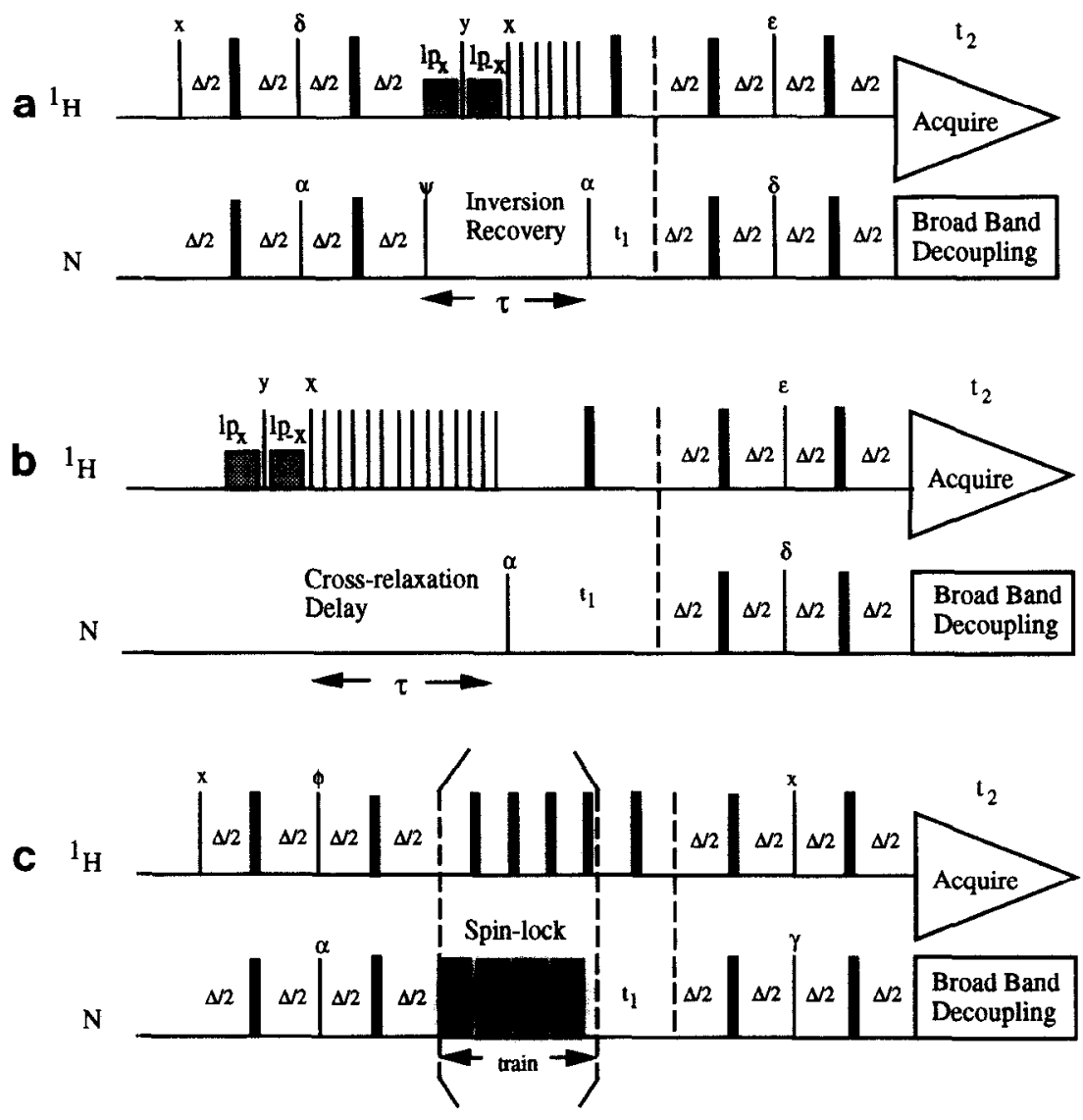

FIG. 2. Two-dimensional heteronuclear pulse sequences for measuring the six relaxation parameters discussed in the text. The upper trace indicates proton pulses while the lower trace indicates heteronucleus ( $N$ spin) pulses. To compensate for relaxation losses, $\Delta / 2$ is customarily set to be slightly less than $1 / 4 J_{\mathrm{NH}}$, i.e., $\approx 2.3 \mathrm{~ms}$. The minimum phase cycle for all sequences is eight steps with the receiver phase alternating as $+x,-x,-x,+x,-x,+x,+x,-x$. Pulse phases are illustrated above the pulses themselves according to the following key: $\alpha=+x,-x ; \beta=+y,-y ; \gamma=+x,+x,-x,-x ; \delta=+y,+y,-y,-y ; \epsilon=4(+x)$, $4(-x) ; \phi=4(+y), 4(-y)$. For those sequences using the spin lock, the TPPI phase modulation is done on the first $90^{\circ} \mathrm{N}$ pulse following the $t_{1}$ period. Otherwise, the TPPI phasing occurs before the $t_{1}$ period. (a) $R_{\mathrm{N}}\left(\mathrm{N}_{z}\right)$ pulse sequence using a double-INEPT strategy. The minimum $\tau$ length should allow for both long pulses $\left(\approx 1 \mathrm{~ms}\right.$ each) to be executed prior to the train of $90^{\circ}$ pulses. The $90^{\circ} \mathrm{N}$ pulse just prior to the $\tau$ period is cycled as $\psi=+y,-y,-y,+y$. (b) Heteronuclear cross-relaxation (NOE) sequence for measuring $R_{\mathrm{N}}\left(\mathrm{H}_{z}^{\mathrm{N}} \rightarrow \mathrm{N}_{z}\right)$. (c) $R_{\mathrm{N}}\left(\mathrm{N}_{x, y}\right)$ sequence. Typical spin-lock strengths are 2.5 to $3 \mathrm{kHz}$. The spin lock consists of contiguous $180^{\circ}$ pulses on $\mathrm{N}$ with alternating phases $\pm x$. Hard proton $180^{\circ}$ pulses are regularly interspersed after an even number of contiguous $\mathrm{N}$ pulses. (d) $R_{\mathrm{NH}}\left(2 \mathrm{H}_{z}^{\mathrm{N}} \mathrm{N}_{z}\right.$ ) pulse sequence for measuring the relaxation rate of longitudinal two-spin order, or " $z z$ " magnetization. (e) $R_{\mathrm{NH}}\left(2 \mathrm{H}_{z}^{\mathrm{N}} \mathrm{N}_{x, y}\right.$ ) pulse sequence for measuring the decay of antiphase coherence. The spin lock is the same as that in sequence (c) but with only a single proton $180^{\circ}$ hard pulse in the center of the relaxation delay. (f) N-spin-relayed NOESY sequence for measuring spin-lattice relaxation rates $R_{\mathrm{H}}\left(\mathrm{H}_{z}^{\mathrm{N}}\right)$ for the $\mathrm{H}^{\mathrm{N}}$ protons. 

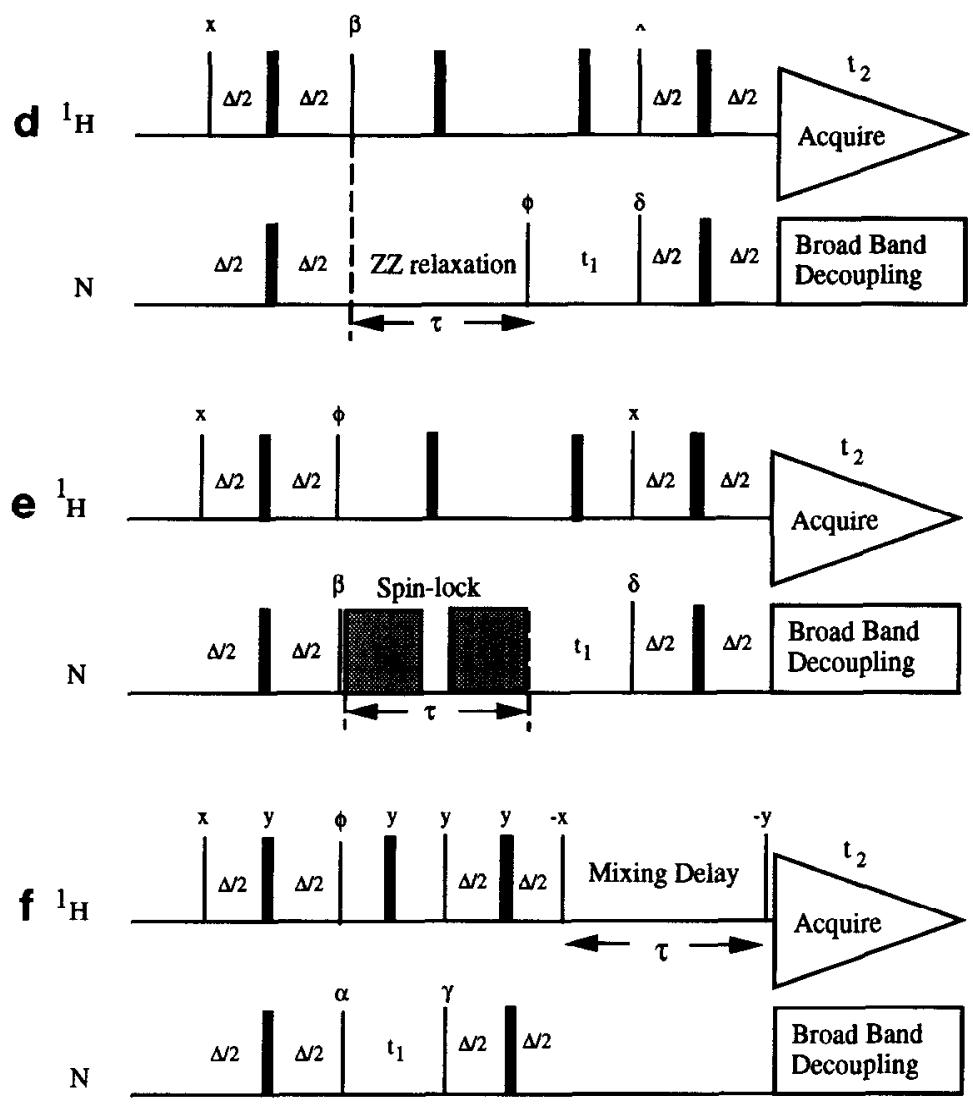

FIG. 2-Continued

already been given in the literature $(1-5,20,21)$. In all cases, a variable relaxation delay is incorporated into a double- or single-INEPT-type (36) inverse-detected heteronuclear correlation sequence. One-spin relaxation rates $\left[R_{\mathrm{N}}\left(\mathrm{N}_{z}\right)\right.$ and $R_{\mathrm{N}}\left(\mathrm{N}_{x, y}\right)$ ] can also be measured by using a double-DEPT strategy $(1,37)$. Sign discrimination in $F_{1}$ can be achieved with TPPI phase modulation (38). In contrast to ${ }^{13} \mathrm{C}$ studies, solvent suppression is a major concern in ${ }^{15} \mathrm{~N}$ relaxation measurements. Initial presaturation of the solvent line can be used if the solution conditions prohibit rapid hydrogen exchange. If this is not possible, then techniques such as the long pulse methods of Messerle et al. (39) can be used. In these methods, long ${ }^{1} \mathrm{H}$ pulses are used to spoil magnetizations not associated with the $\mathrm{NH}^{\mathrm{N}}$ spin system prior to $t_{2}$ detection. Specifically, the phases of these long pulses are parallel to those of the desired coherences and are orthogonal to the undesired coherences (i.e., solvent). The undesired coherences are destroyed by the applied RF field inhomogeneity. The pulses have a maximum length of a couple of milliseconds and use no attenuation. They can be applied when the magnetization consists of proton antiphase coherence (e.g., $2 \mathrm{H}_{x, y}^{\mathrm{N}} \mathrm{N}_{z}$ ) during the reverse INEPT, or just prior to detection. We now discuss specific aspects of the $2 \mathrm{D}$ sequences in turn.

(i) $R_{N}\left(N_{z}\right)$ and $R_{N}\left(H_{z}^{N} \rightarrow N_{z}\right)$ measurements. The spin-lattice relaxation rates of 
the $\mathrm{N}$ spins, $R_{\mathrm{N}}\left(\mathrm{N}_{z}\right)$, can be measured with the sequence shown in Fig. 2a. The Nspin magnetization is inverted for the variable delay $\tau$ after a refocused INEPT. Note that the refocused INEPT forces a nonequilibrium condition of zero $\mathrm{H}_{z}^{\mathrm{N}}$ magnetization by rotating the proton spins onto the transverse plane. If no additional pulses are applied during the $\tau$ delay, immediate cross relaxation, due to the heteronuclear dipolar interaction, will ensue between the $H_{z}^{N}$ and $N_{z}$ magnetizations, resulting in a biexponential recovery of $\mathrm{N}_{z}(30)$. The rate of recovery will then depend on both the spin-lattice relaxation rate $R_{\mathrm{N}}\left(\mathrm{N}_{z}\right)$ and the cross-relaxation rate $R_{\mathrm{N}}\left(\mathrm{H}_{z}^{\mathrm{N}} \rightarrow \mathrm{N}_{z}\right)$. Thus, subsequent attempts to equate the recovery rate to $R_{\mathrm{N}}\left(\mathrm{N}_{z}\right)$ will have some error. The severity of error introduced will depend on the relative magnitudes of $R_{\mathrm{N}}\left(\mathrm{H}_{z}^{\mathrm{N}} \rightarrow \mathrm{N}_{z}\right)$ to $R_{\mathrm{N}}\left(\mathrm{N}_{z}\right)$, which is essentially a measure of the heteronuclear NOE. If $R_{\mathrm{N}}\left(\mathrm{H}_{z}^{\mathrm{N}} \rightarrow\right.$ $\left.\mathrm{N}_{z}\right)$ is much smaller than the spin-lattice relaxation rate, $R_{\mathrm{N}}\left(\mathrm{N}_{z}\right)$, then this error will be insignificant. This may be the case for rigid $\mathrm{NH}^{\mathrm{N}}$ bonds in a larger proteins which tumble more slowly in solution (i.e., overall rotational correlation times $\geqslant 10 \mathrm{~ns}$ ). However, if the bonds experience significant internal mobility, then cross-relaxation effects cannot be ignored. Since these are the cases of interest, it is generally desirable to suppress the cross-relaxation effects throughout the relaxation period. As stated above, this is achieved by saturating the protons during the $\tau$ delay as shown in Fig. $2 \mathrm{a}$. The saturation is maintained by a combination of long pulses $(\approx 1 \mathrm{~ms})$ followed by a train of hard $90^{\circ}$ proton pulses. The saturation effectively reduces the longitudinal magnetization kinetics from those of a two-spin system to those of a one-spin system insofar as the heteronuclear dipolar interaction is concerned. The proton saturation also suppresses the aforementioned dipolar-CSA cross-correlation effects. In particular, the cross relaxation to longitudinal two-spin order, $2 \mathrm{H}_{z}^{\mathrm{N}} \mathrm{N}_{z}$ is suppressed since the proton saturation forces $2 \mathrm{H}_{z}^{\mathrm{N}} \mathrm{N}_{z}$ to zero. This essentially follows the technique of Boyd et al. (20), who used proton broadband decoupling to achieve saturation of the attached protons. Thus, cross-relaxation pathways stemming from both the heteronuclear dipolar $\mathrm{NH}^{\mathrm{N}}$ interaction and the dipolar-CSA cross correlation are suppressed in the pulse sequence in Fig. 2a; therefore, $\mathrm{N}_{z}$ magnetization recovers monoexponentially at the rate $R_{\mathrm{N}}\left(\mathrm{N}_{z}\right)$, until it reaches the steady-state heteronuclear NOE intensity. Clearly, the same considerations for applying the proton saturation hold when the doubleDEPT strategy is used.

The sequence for measuring the heteronuclear cross-relaxation rates $R_{\mathrm{N}}\left(\mathrm{H}_{z}^{\mathrm{N}} \rightarrow\right.$ $\mathrm{N}_{z}$ ) and NOE intensities is shown in the pulse sequence in Fig. 2b. The protons are saturated in the same manner as in the $R_{\mathrm{N}}\left(\mathrm{N}_{z}\right)$ experiment in Fig. 2a for progressively longer times $\tau$. Thus, the $\mathrm{N}_{z}$ magnetization begins at the equilibrium Zeeman value for $\tau=0$ and reaches the steady-state heteronuclear NOE value for long $\tau$. As a result, the initial slope of $\mathrm{N}_{z}$ with respect to $\tau$ is proportional to $R_{\mathrm{N}}\left(\mathrm{H}_{z}^{\mathrm{N}} \rightarrow \mathrm{N}_{z}\right)$. Alternatively, the $R_{\mathrm{N}}\left(\mathrm{H}_{z}^{\mathrm{N}} \rightarrow \mathrm{N}_{z}\right)$ rates can be obtained with the steady-state NOE intensities and the $R_{\mathrm{N}}\left(\mathrm{N}_{z}\right)$ values using Eq. [9]. In principle, only the $\tau=0$ and $\tau=\infty$ spectra are necessary to obtain the NOE intensities. However, a series of spectra should still be acquired for these $\tau$ values to get an estimate for the error in the recorded NOE values. This is important if the NOE values are small.

(ii) $R_{N}\left(N_{x, y}\right)$ measurements. Figure $2 \mathrm{c}$ shows a sequence for measuring the inphase transverse relaxation rates, $R_{\mathrm{N}}\left(\mathrm{N}_{x, y}\right)$. The sequence uses a low-power spin-lock consisting of contiguous phase-alternating $180^{\circ}$ pulses to maintain transverse $\mathrm{N}_{x}$ mag- 
netization for the relaxation delay $\tau$. Adopting procedures analogous to that of Palmer et al. (21), hard $180^{\circ}$ pulses on the attached $\mathrm{H}^{\mathrm{N}}$ protons are periodically inserted between fixed lengths of spin locking. The spin lock not only suppresses "fan out" of the $\mathrm{N}_{x}$ coherence arising from inhomogeneities in the static field, but also prevents the oscillation between in-phase coherence and antiphase $2 \mathrm{H}_{z}^{\mathrm{N}} \mathrm{N}_{y}$ coherence (27). Erroneously fast $R_{\mathrm{N}}\left(\mathrm{N}_{x, y}\right)$ rates will be recorded if significant antiphase coherence is allowed to develop during the $\tau$ period. As seen in Eq. [11], antiphase coherence relaxes considerably faster than its in-phase counterpart due to proton-proton dipolar relaxation. The $\rho_{\mathrm{H}^{\mathrm{N}_{\mathrm{H}}}}$ term given in Eq. [12] expresses this effect. Consequently, a significant fraction of the in-phase coherence that evolves into antiphase coherence is irreversibly lost. In our experience with ${ }^{15} \mathrm{~N}$ relaxation, failure to compensate for these effects can produce apparent $R_{\mathrm{N}}\left(\mathrm{N}_{x, y}\right)$ values which are faster than those obtained with a spin lock by as much as twofold. This is discussed in more detail elsewhere $(27,33)$. In contrast, erroneously long $R_{\mathrm{N}}\left(\mathrm{N}_{x, y}\right)$ values will be recorded if the effects of the dipolar-CSA cross correlation are left unchecked. The cross-correlation errors can be effectively removed by the method of Palmer et al. (21), which applies hard $180^{\circ}$ pulses to the amide $\mathrm{H}^{\mathrm{N}}$ protons after every even echo of a CPMG $(40,41)$ pulse train on the $\mathrm{N}$ spins. In the spin-lock version of this experiment shown in Fig. 2c, the $180^{\circ}$ proton pulses occur after a set number of even, phase-alternating, and contiguous $180^{\circ}{ }^{15} \mathrm{~N}$ pulses constituting a low-power spin lock on the order of $3 \mathrm{~ms}$. No significant in-phase and antiphase evolution of the $\mathrm{N}$ spins is expected to take place during the proton $180^{\circ}$ pulse $(\approx 17 \mu \mathrm{s})$. Rigorously, the sequence in Fig. $2 \mathrm{c}$ measures the aforementioned spin-lattice relaxation rate in the rotating frame, $R_{\mathrm{N}}\left(\mathrm{N}_{\rho z^{\prime}}\right)$, given in Eq. [13]. As stated, if the spin lock is sufficiently on resonance for all $\mathrm{N}$ spins and if $J(\omega$ $\left.\pm \omega_{\mathrm{e}}\right) \approx J(\omega)$, then $R_{\mathrm{N}}\left(\mathrm{N}_{\rho z^{\prime}}\right)$ is identical to $R_{\mathrm{N}}\left(\mathrm{N}_{x, y}\right)(27)$. In our amide ${ }^{15} \mathrm{~N}$ relaxation studies of the protease inhibitor eglin $\mathrm{c}\left(M_{\mathrm{r}}=8111,70\right.$ residues $)$, the amide ${ }^{15} \mathrm{~N}$ resonances are completely contained within a spectral width of $1200 \mathrm{~Hz}$ at a field of $11.7 \mathrm{~T}$. Under a $2.5 \mathrm{kHz}$ spin lock, this results in tip angles of $77^{\circ}$ at $\pm 600 \mathrm{~Hz}$. Since the leading term of $R_{\mathrm{N}}\left(\mathrm{N}_{\rho z^{\prime}}\right)$ varies as $\sin ^{2}(\beta)$, where $\beta$ is the tip angle, the spin lock can be reasonably approximated as on resonance for all cross peaks within the spectral width. For significantly wider spectral widths, the relaxation rates can be measured with different spin-lock carrier positions such that the desired spectral range is covered with minimal off-resonance errors. The applicability of the approximation $J\left(\omega \pm \omega_{\mathrm{e}}\right)$ $\approx J(\omega)$ can be checked by measuring the relaxation rates as a function of the spinlock field strength. In particular, our preliminary studies on eglin $\mathrm{c}$ show that relaxation rates exhibit no significant variation as the spin-lock strength is varied from $3 \mathrm{kHz}$ down to $700 \mathrm{~Hz}$ for the on-resonance cross peaks. Therefore, the identification of $R_{\mathrm{N}}\left(\mathrm{N}_{\rho z^{\prime}}\right)$ with $R_{\mathrm{N}}\left(\mathrm{N}_{x, y}\right)$ appears reasonablc in this casc. Note that we need worry only about the approximation $J\left(\omega \pm \omega_{\mathrm{e}}\right) \approx J(\omega)$ for $\omega \neq 0$. A significant difference between $J\left(\omega_{\mathrm{e}}\right)$ and $J(0)$ is quite tolerable since no additional unknowns are introduced. $J\left(\omega_{\mathrm{e}}\right)$ simply replaces $J(0)$ as the lowest frequency spectral density sampling to be solved for. One can also use the CPMG pulse train to measure $R_{\mathrm{N}}\left(\mathrm{N}_{x, y}\right)$ and avoid this concern altogether. However, the spacing between consecutive $180^{\circ}$ refocusing pulses must be much smaller than $1 / 2 J_{\mathrm{NH}}\left(5.5 \mathrm{~ms}\right.$ for the case of ${ }^{15} \mathrm{~N}-{ }^{1} \mathrm{H}$ one-bond coupling $)$. If this cannot be achieved, then erroneously fast relaxation times will be recorded as described above. It is therefore advisable to measure the CPMG rates with variable 
pulse spacings to ensure that there is no uniform decrease of relaxation rates as the pulse spacing is narrowed. Uniform decreases would imply that the antiphase relaxation is still significantly contaminating the desired in-phase measurements. Thus, the advantage of the spin-lock experiment is that this concern is eliminated. Finally, it should be noted that measurement of $R_{\mathrm{N}}\left(\mathrm{N}_{\rho z^{\prime}}\right)$ as a function of spin-lock field strength is of interest not only for reasons described above, but also if one is dealing with resonances that give indication of a chemical-exchange process. In such cases, the field dependence of $R_{\mathrm{N}}\left(\mathrm{N}_{\rho z^{\prime}}\right)$ can be used to characterize exchange processes with rates on the order of the spin-lock field strength, $\omega_{1}$. These techniques have been developed by Deverell et al. (42).

(iii) $R_{N H}\left(2 H_{z}^{N} N_{z}\right)$ measurements and $R_{N H}\left(2 H_{z}^{N} N_{x, y}\right)$ measurements. Figure $2 \mathrm{~d}$ shows the pulse sequence for measuring the decay of longitudinal two-spin order, $2 \mathrm{H}_{z}^{\mathrm{N}} \mathrm{N}_{z}$. Longitudinal two-spin order is created immediately after the second $90^{\circ}$ proton pulse. After the $\tau$ delay, it is converted into antiphase ${ }^{15} \mathrm{~N}$ coherence for subsequent $t_{1}$ labeling and inverse detection. In the sequence in Fig. $2 \mathrm{e}$, the aforementioned antiphase coherence is maintained with low-power spin lock prior to the $t_{1}$ labeling, in order to measure the antiphase relaxation rate. The spin lock is of the same type as that described for the $R_{\mathrm{N}}\left(\mathrm{N}_{x, y}\right)$ measurements in Fig. $2 \mathrm{c}$. The essential difference is that only one $180^{\circ}$ pulse is applied to attached $\mathrm{H}^{\mathrm{N}}$ protons during the relaxation delay. An identical $180^{\circ}$ pulse is placed in the middle of the relaxation delay for the $R_{\mathrm{INH}}\left(2 \mathrm{H}_{z}^{\mathrm{N}} \mathrm{N}_{z}\right)$ sequence in Fig. $2 \mathrm{~d}$. As discussed by Palmer et al. $(21)$, this pulse helps reduce dipolar-CSA cross-correlation effects. In analogy with the in-phase measurements just described, the actual parameter being measured in Fig. $2 \mathrm{e}$ is $R_{\mathrm{NH}}\left(2 \mathrm{H}_{z}^{\mathrm{N}} \mathrm{N}_{\rho z^{\prime}}\right)$. Given the same provisions concerning off-resonance effects and spectral densities as those described above, $R_{\mathrm{NH}}\left(2 \mathrm{H}_{z}^{\mathrm{N}} \mathrm{N}_{\rho z^{\prime}}\right)$ is identical to $R_{\mathrm{NII}}\left(2 \mathrm{H}_{z}^{\mathrm{N}} \mathrm{N}_{x, y}\right)$. Here, the spin lock is necessary to prevent the evolution of antiphase coherence into in-phase coherence. In this way one is assured that the in-phase and antiphase rates are measured separately. Using this experiment, we have verified that the $R_{\mathrm{NH}}\left(2 \mathrm{H}_{2}^{\mathrm{N}} \mathrm{N}_{x, y}\right)$ rates are significantly faster than the corresponding $R_{\mathrm{N}}\left(\mathrm{N}_{x, y}\right)$ rates for all amide ${ }^{15} \mathrm{~N}-{ }^{1} \mathrm{H}$ spin systems in the 70-residue protein eglin $\mathrm{c}(27)$.

(iv) $R_{H}\left(H_{z}^{N}\right)$ measurements. The spin-lattice relaxation rates of the $\mathrm{H}^{\mathrm{N}}$ protons can be measured using the sequence shown in Fig. $2 \mathrm{f}$. This sequence is an N-spinrelayed NOESY experiment (43). Specifically, a ${ }^{1} \mathrm{H}-{ }^{1} \mathrm{H}$ NOESY mixing period is appended just after the double-INEPT heteronuclear correlation experiment. Thus, after the $\mathrm{H}^{\mathrm{N}}$ spins are labeled with the $\mathrm{N}$-spin chemical-shift frequencies $\Omega_{\mathrm{N}}$, they are rotated onto the $\pm z$ axis in an alternate fashion by a $90_{-x}^{\circ}\left({ }^{1} \mathrm{H}\right)$ pulse so that NOEs can develop during the $\tau$ period. $\mathrm{H}^{i}$ protons not bound to the $\mathrm{N}$ spins are initially placed on the $-y$ axis and do not experience any of the antecedent phase cycling. These protons are rotated back to the $+z$ axis at the start of the mixing period, $\tau$, for all scans. In the resulting 2D spectrum, the cross-peak intensities of the direct $\mathrm{NH}^{\mathrm{N}}$ correlations follow behavior similar to that of the diagonal peaks in a 2D homonuclear NOESY and tend to 0 for long $\tau$. Additionally, cross relaxation between spatially close proton pairs $\mathrm{H}^{\mathrm{N}} \mathrm{H}^{i}$ will yield cross peaks at $\Omega_{\mathrm{N}}$ (the frequency label of the $\mathrm{H}^{\mathrm{N}}$ spin) along $F_{1}$ and at $\Omega_{\mathrm{H}^{i}}$ along $F_{2}$. A series of these $\mathrm{N}$-spin-relayed NOESY spectra is acquired for variable mixing delays $\tau$. Since the directly bound amide protons $\mathrm{H}^{\mathrm{N}}$ are inverted at different times, while all other protons are placed on the $+z$ axis, the 
relaxation behavior is expected to be similar to that seen in selective $T_{1}$ experiments. The relaxation of the nonequilibrium $\mathrm{H}_{z}^{\mathrm{N}}$ magnetizations can then be approximated by exponential decays, to yield $R_{\mathrm{H}}\left(\mathrm{H}_{z}^{\mathrm{N}}\right)$ previously shown in Eq. [13]. Alternatively, the cross-peak intensities can be fitted to a polynomial in the relaxation (mixing) delay $\tau$. These methods follow that described by Hyberts and Wagner (44). In particular, the fitted linear coefficient of the direct cross peaks then supplies the desired rate, $R_{\mathrm{H}}\left(\mathrm{H}_{z}^{\mathrm{N}}\right)$.

\section{EXPERIMENTAL RESULTS}

We have recently applied these techniques to the uniformly ${ }^{15} \mathrm{~N}$-enriched protein eglin $\mathrm{c}$ in order to investigate the spectral densities of the backbone amide ${ }^{15} \mathrm{~N}-{ }^{1} \mathrm{H}$ bond vectors. Eglin $\mathrm{c}$ is a protein of 70 residues. It inhibits proteases, such as elastase, subtilisin, thermistase, and chymotrypsin. The sample was degassed prior to the measurements. The protein concentration was $3.8 \mathrm{~m} M$ and the $\mathrm{pH}$ was set to 3.0 . Twodimensional spectra for all six relaxation series were acquired on a Bruker AMX-500 spectrometer at $36^{\circ} \mathrm{C}$. The pulse sequences not involving amide ${ }^{1} \mathrm{H}$ saturation during the relaxation delay typically demanded 1.5 days of instrument time for a nine $2 \mathrm{D}$ spectra series. The longitudinal $R_{\mathrm{N}}\left(\mathrm{N}_{z}\right)$ and $R_{\mathrm{N}}\left(\mathrm{H}_{z}^{\mathrm{N}} \rightarrow \mathrm{N}_{z}\right)$ experiments demand somewhat longer measuring times ( 2.5 and 4 days, respectively) owing to ${ }^{15} \mathrm{~N}$ relaxation delays on the order of seconds and the lack of an initial heteronuclear polarization transfer in the heteronuclear NOE $R_{\mathrm{N}}\left(\mathrm{H}_{z}^{\mathrm{N}} \rightarrow \mathrm{N}_{z}\right)$ experiment. The data sets consisted of $128 t_{1}$ blocks of 2048 complex $t_{2}$ points. Sign discrimination in the $F_{1}\left({ }^{15} \mathrm{~N}\right)$ dimension was achieved using the TPPI technique (38). The ${ }^{15} \mathrm{~N}$ spin-lock field strengths were set to $2500 \mathrm{~Hz}$ for the two transverse relaxation experiments shown in Figs. 2c and $2 \mathrm{e}$. This amounts to minimum tip angles of about $77^{\circ}$ at the edges of the eglin $\mathrm{c}$ ${ }^{15} \mathrm{~N}$ sweep width of $1200 \mathrm{~Hz}$. Thus, the maximum overestimate of $R_{\mathrm{N}}\left(\mathrm{N}_{x, y}\right)$ and $R_{\mathrm{NH}}\left(2 \mathrm{H}_{z}^{\mathrm{N}} \mathrm{N}_{x, y}\right)$ is about $6 \%$ for resonances at the extreme edges of the eglin ${ }^{15} \mathrm{~N}$ sweep width. The transverse experiments used ${ }^{15} \mathrm{~N}$ spin locks containing regularly interspersed ${ }^{1} \mathrm{H} 180^{\circ}$ pulses every $3.2 \mathrm{~ms}$. We note that the single $180^{\circ}$ proton pulses in the center of the relaxation delays for the $R_{\mathrm{NH}}\left(2 \mathrm{H}_{z}^{\mathrm{N}} \mathrm{N}_{z}\right)$ and $R_{\mathrm{NH}}\left(2 \mathrm{H}_{z}^{\mathrm{N}} \mathrm{N}_{x, y}\right)$ experiments shown in Figs. $2 \mathrm{~d}$ and $2 \mathrm{e}$ are not expected to completely suppress the cross relaxation caused by the dipolar-CSA cross correlation (21). Accordingly, additional cross-relaxation experiments are in progress to better gauge the magnitude of the crosscorrelation effects.

Data analysis was facilitated by the use of the software package PLOT (New Unit Inc., Ithaca, New York). For each relaxation series, the peak intensities of the ${ }^{15} \mathrm{~N}-$ ${ }^{1} \mathrm{H}$ correlations were measured by integrating slices along the ${ }^{1} \mathrm{H}\left(F_{2}\right)$ dimension through the cross-peak maxima in the constituent $2 \mathrm{D}$ spectra. Relaxation rates were extracted by fitting the peak intensities to single-exponential functions using the Levenburg-Marquardt nonlinear least-squares (45) routine in PLOT. Examples of the six resulting fits for Arg 51 are shown in Fig. 3. For the well-structured portion of the protein (residues 8-70), the average values of the six rates were 2.5, 4.2, 8.1, 6.4, 4.5, and $0.08 \mathrm{~s}^{-1}$ for the $R_{\mathrm{N}}\left(\mathrm{N}_{z}\right), R_{\mathrm{N}}\left(\mathrm{N}_{x, y}\right), R_{\mathrm{NH}}\left(2 \mathrm{H}_{z}^{\mathrm{N}} \mathrm{N}_{x, y}\right), R_{\mathrm{NH}}\left(2 \mathrm{H}_{z}^{\mathrm{N}} \mathrm{N}_{z}\right), R_{\mathrm{H}}\left(\mathrm{H}_{z}^{\mathrm{N}}\right)$, and $R_{\mathrm{N}}\left(\mathrm{H}_{z}^{\mathrm{N}} \rightarrow \mathrm{N}_{z}\right)$, respectively. Additionally, the average fractional uncertainties 
in the fitted rates calculated from the function fitting routine were $\pm 1.5,4.5,5,5,3.5$, and $2.5 \%$ for $R_{\mathrm{N}}\left(\mathrm{N}_{z}\right), R_{\mathrm{N}}\left(\mathrm{N}_{x, y}\right), R_{\mathrm{NH}}\left(2 \mathrm{H}_{z}^{\mathrm{N}} \mathrm{N}_{x, y}\right), R_{\mathrm{NH}}\left(2 \mathrm{H}_{z}^{\mathrm{N}} \mathrm{N}_{z}\right), R_{\mathrm{H}}\left(\mathrm{H}_{z}^{\mathrm{N}}\right)$, and $R_{\mathrm{N}}\left(\mathrm{H}_{z}^{\mathrm{N}} \rightarrow \mathrm{N}_{z}\right)$, respectively.

Using Eqs. [17]-[22] above, we have calculated the five spectral density samplings for all backbone amide ${ }^{15} \mathrm{~N}-{ }^{1} \mathrm{H}$ bond vectors in eglin c. Two examples of the resulting spectral density plots are shown in Figs. $4 \mathrm{a}$ and $4 \mathrm{~b}$. The samplings are plotted against frequency given in megahertz. As the error bars indicate, a precise determination of the higher frequency samplings, $J\left(\omega_{\mathrm{H}^{\mathrm{N}}}-\omega_{\mathrm{N}}\right)$ and $J\left(\omega_{\mathrm{H}^{\mathrm{N}}}\right)$, can be difficult since the errors become comparable to the $J(\omega)$ values themselves.

In order to make comparisons between the $J(\omega)$ values belonging to different residues, or between the experimental values and those obtained from motional models, it is necessary to assess the sensitivity of the $J(\omega)$ values to errors in the rate measurements. Equations [17]-[22] allow us to perform an initial, elementary error analysis of the $J(\omega)$ values. If the rate measurement uncertainties, $\delta R_{i}$, are independent and due only to random errors, then the net uncertainty propagated to a particular $J(\omega)$ consists simply of the weighted sum, in quadrature, of the $\delta R_{i}$. That is, for each sampling we have

$$
(\delta J)^{2}=\sum_{i=1}^{6} c_{i}^{2}\left(\delta R_{i}\right)^{2} .
$$

The $c_{i}^{2}$ weights are the squares of the various rate coefficients seen in Eqs. [17]-[21] and the $\delta J$ denotes the propagated uncertainty in a given spectral density sampling. The error bars shown in Figs. $4 \mathrm{a}$ and $4 \mathrm{~b}$ are derived from the resulting $\delta J$ in Eq. [23]. Application of Eq. [23] reveals that the uncertainties of the transverse relaxation rates, $R_{\mathrm{N}}\left(\mathrm{N}_{x, y}\right)$ and $R_{\mathrm{NH}}\left(2 \mathrm{H}_{z}^{\mathrm{N}} \mathrm{N}_{x, y}\right)$, propagate significantly larger uncertainties to a given $J(\omega)$ value than the longitudinal relaxation rates $R_{\mathrm{N}}\left(\mathrm{N}_{z}\right)$ and $R_{\mathrm{NH}}\left(2 \mathrm{H}_{z}^{\mathrm{N}} \mathrm{N}_{z}\right)$. This is due to the fact that the transverse rates are weighted more heavily in Eqs. [17]-[22], and that their measurements are typically less precise. That is, the transverse rates contribute relatively larger $c_{i}$ and $\delta R_{i}$ values to the sum in Eq. [23] than the longitudinal rates. Random errors in the amide proton spin-lattice relaxation rates, $R_{\mathrm{H}}\left(\mathrm{H}_{z}^{\mathrm{N}}\right)$, are another potent source of uncertainty. This is because the $R_{\mathrm{H}}\left(\mathrm{H}_{z}^{\mathrm{N}}\right)$ contribute to all of the $J(\omega)$ samplings as well as $\rho_{\mathrm{H}^{\mathrm{N}} \mathrm{H}}$; hence, they contribute their random errors to all of these values. In particular, we note that $J\left(\omega_{\mathrm{H}^{\mathrm{N}}}-\omega_{\mathrm{N}}\right)$ is extremely sensitive to random errors in $R_{\mathrm{H}}\left(\mathrm{H}_{z}^{\mathrm{N}}\right)$. This is because $J\left(\omega_{\mathrm{H}^{\mathrm{N}}}-\omega_{\mathrm{N}}\right)$ has the largest $R_{\mathrm{H}}\left(\mathrm{H}_{z}^{\mathrm{N}}\right)$ rate

FIG. 3. Examples of relaxation curves for Arg 51 resulting from the six experiments discussed in the text. Intensities were measured by integrating cross peaks along the $F_{2}\left({ }^{1} \mathrm{H}\right)$ dimension through the cross-peak maxima. (a) $R_{\mathrm{N}}\left(\mathrm{N}_{z}\right)$ fit consisting of 11 points at $10,50,100,150,200,300,400,500,800,2000$, and 3000 ms. The fitted decay rate $R_{\mathrm{N}}\left(\mathrm{N}_{z}\right)=2.5 \pm 0.03 \mathrm{~s}^{-1}$. (b) $R_{\mathrm{N}}\left(\mathrm{N}_{x, y}\right)$ fit consisting of 9 points at $6.4,12.8,19.2$, $51.2,76.8,102.4,128.0,172.8$, and $192.0 \mathrm{~ms} . R_{\mathrm{N}}\left(\mathrm{N}_{x, y}\right)=4.4 \pm 0.08 \mathrm{~s}^{-1}$. (c) $R_{\mathrm{NH}}\left(2 \mathrm{H}_{z}^{\mathrm{N}} \mathrm{N}_{x, y}\right)$ fit with data points at $6.4,12.8,19.2,38.4,51.2,76.8,102.4,128.0$, and $172.8 \mathrm{~ms} . R_{\mathrm{NH}}\left(2 \mathrm{H}_{z}^{\mathrm{N}} \mathrm{N}_{x, y}\right)=7.3 \pm 0.11 \mathrm{~s}^{-1}$. (d) $R_{\mathrm{IHH}}\left(2 \mathrm{H}_{z}^{\mathrm{N}} \mathrm{N}_{z}\right)$ fit with 9 data points at $2,10,20,30,50,70,100,130$, and $170 \mathrm{~ms} . R_{\mathrm{NH}}\left(2 \mathrm{H}_{z}^{\mathrm{N}} \mathrm{N}_{z}\right)=5.7 \pm$ $0.05 \mathrm{~s} \mathrm{~s}^{-1}$. (e) $R_{\mathrm{H}}\left(\mathrm{H}_{z}^{\mathrm{N}}\right)$ fit with data points at $25,50,75,100,140,180$, and $200 \mathrm{~ms}$. $R_{\mathrm{H}}\left(\mathrm{H}_{z}^{\mathrm{N}}\right)=4.1 \pm 0.08$ $\mathrm{s}^{-1}$. (f) $R_{\mathrm{N}}\left(\mathrm{H}_{z}^{\mathrm{N}} \rightarrow \mathrm{N}_{z}\right)$ fit with data points at $0,50,100,150,200,250,300,400,500,600,1000,2000$, and $3000 \mathrm{~ms}$. $R_{\mathrm{N}}\left(\mathrm{H}_{z}^{\mathrm{N}} \rightarrow \mathrm{N}_{z}\right)$ was calculated to be $0.086 \pm 0.002 \mathrm{~s}^{-1}$ corresponding to an NOE of $0.67 \pm$ 0.02 . 

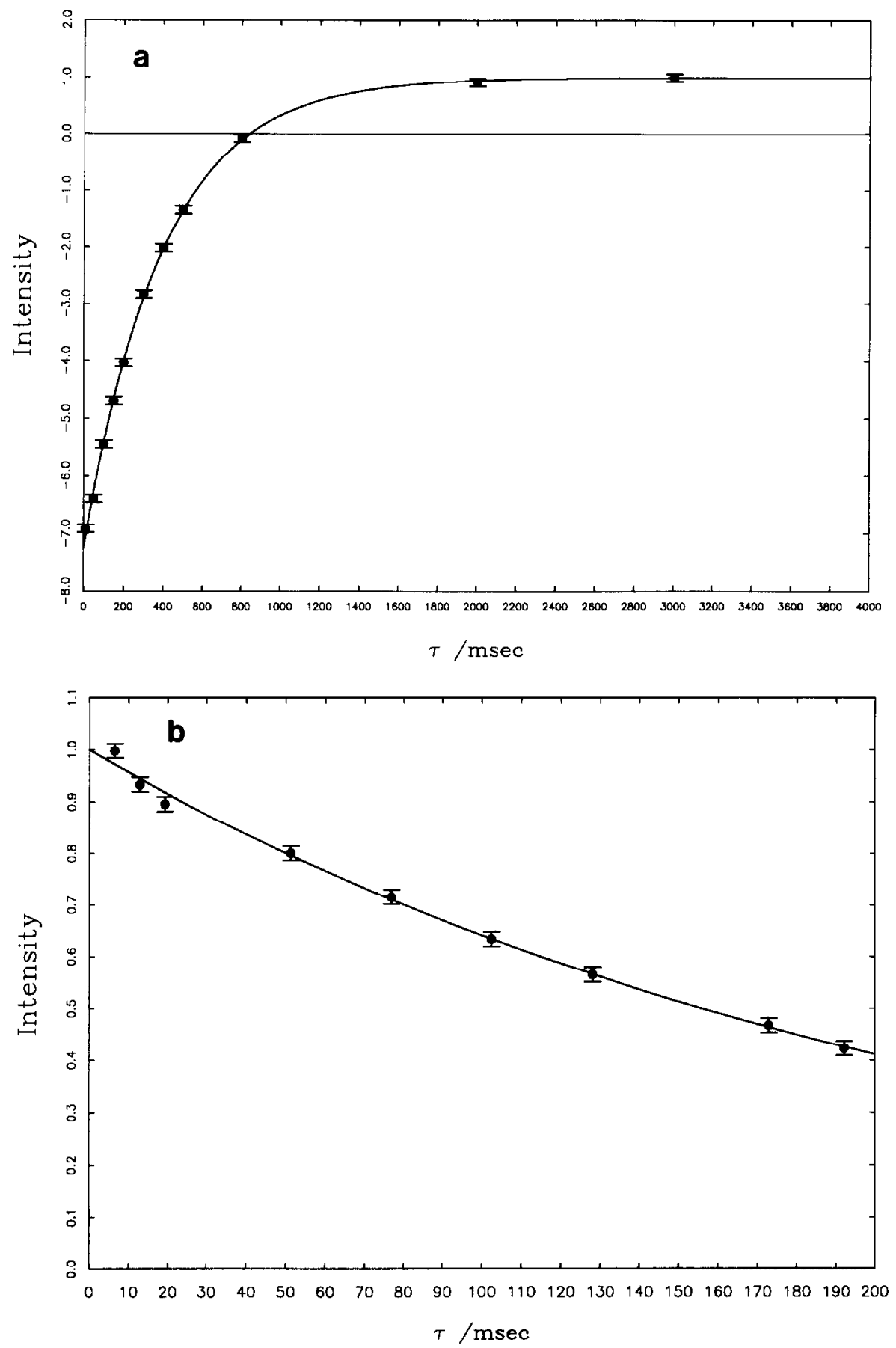
SPECTRAL DENSITIES FROM HOMONUCLEAR MEASUREMENTS
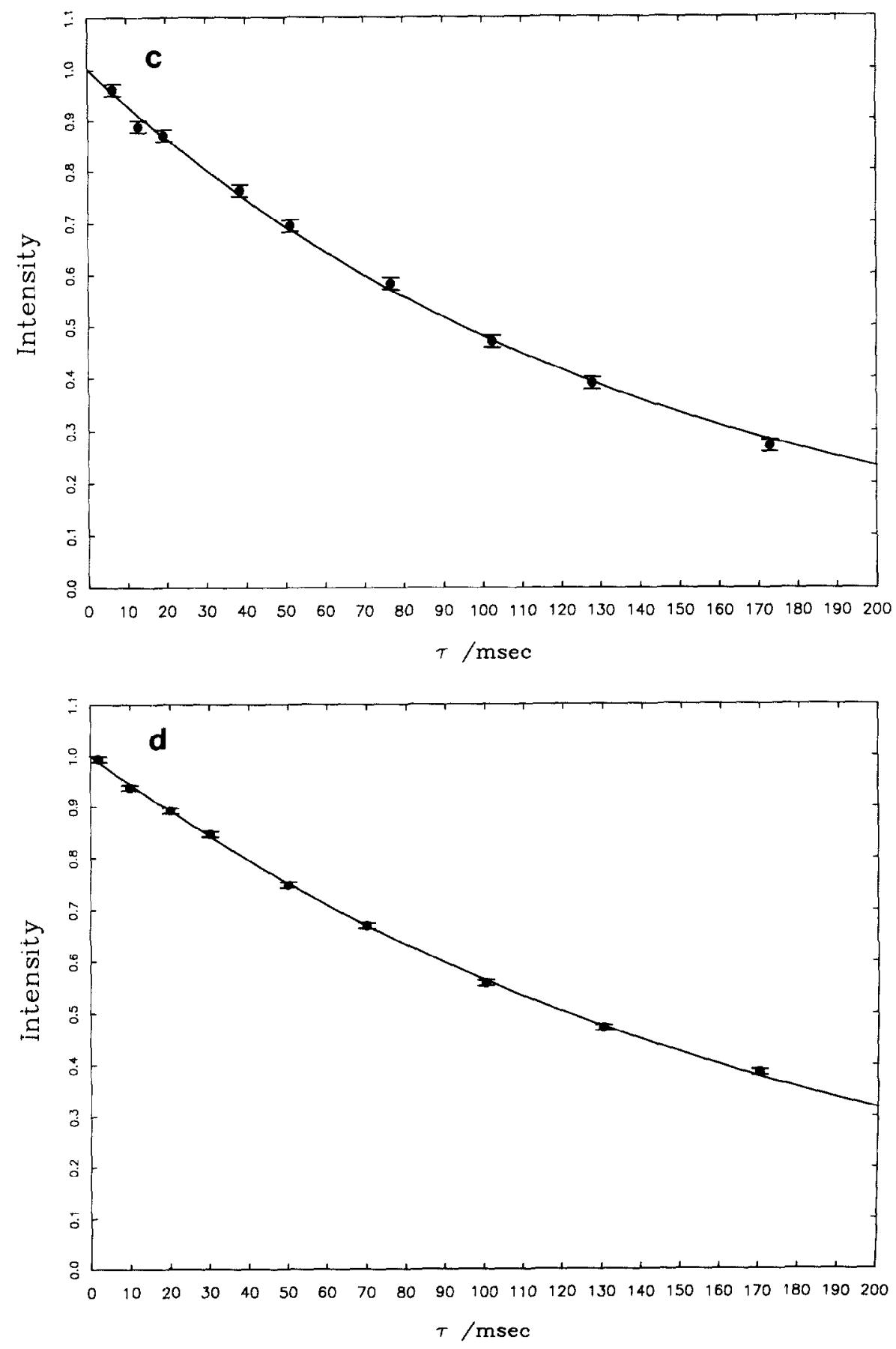

FIG. 3-Continued 

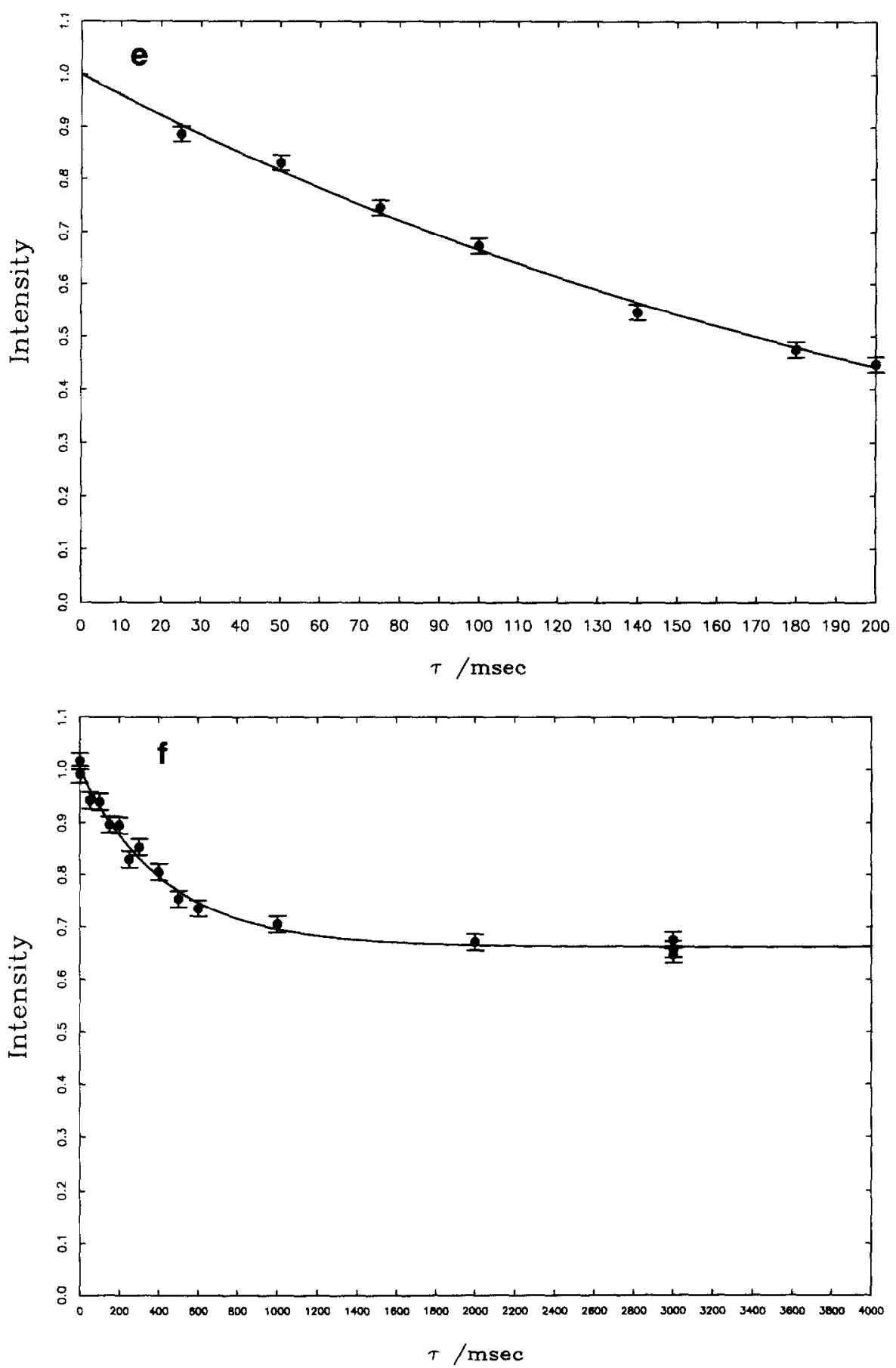

Fig. 3-Continued 

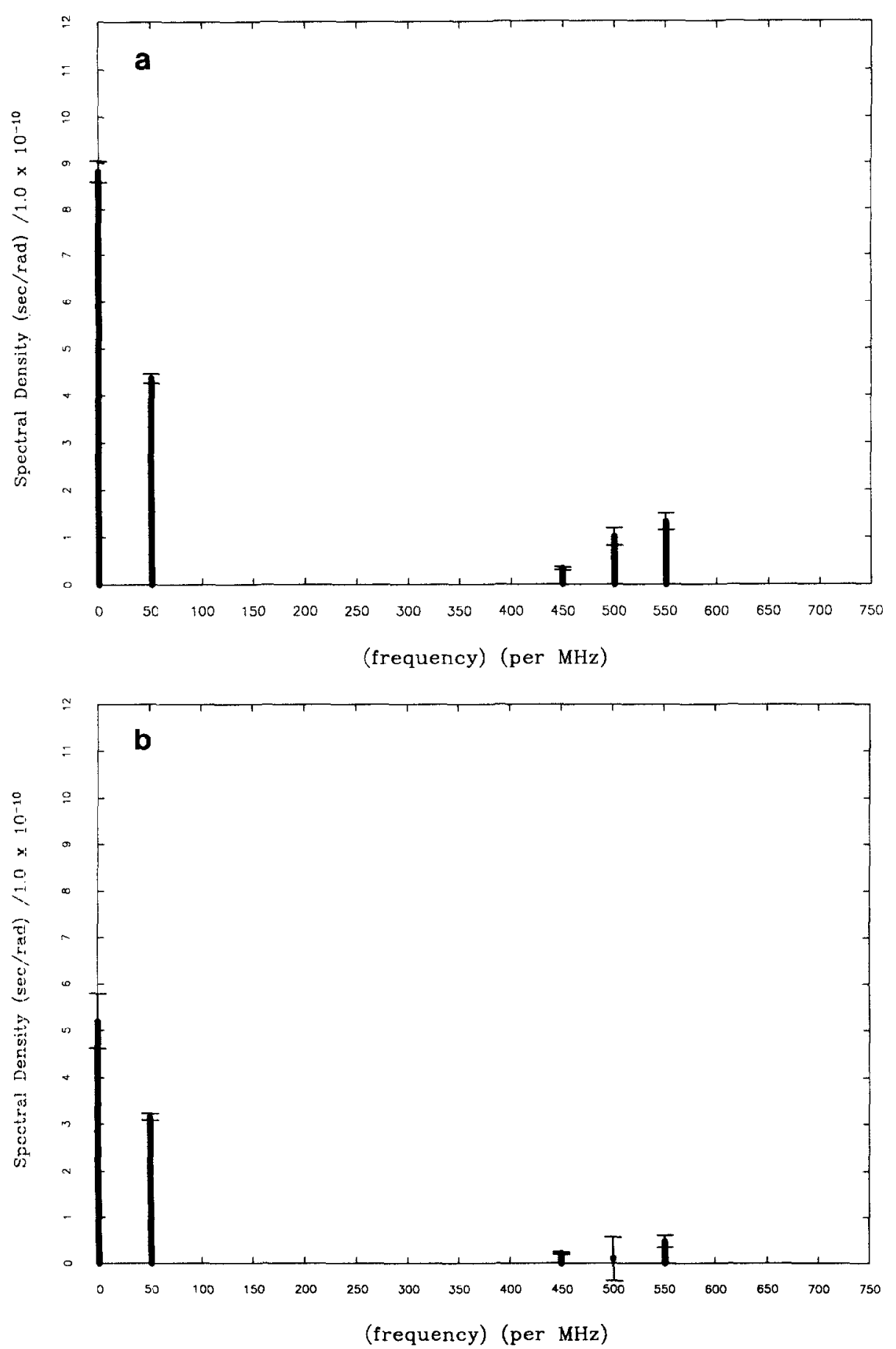

FIG. 4. Spectral density samplings for Arg 51 and Asp 46 as a function of frequency in megahertz. The five samplings frequencies occur at $50,450,500$, and $550 \mathrm{MHz}$ and $2500 \mathrm{~Hz}$. (a) Spectral density samples for Arg 51. The values in order of increasing frequency are $8.8 \pm 0.2,4.4 \pm 0.1,0.33 \pm 0.06,1.0 \pm 0.2$, and $1.3 \pm 0.2$ $\times 10^{-10} \mathrm{~s} / \mathrm{rad}$. (b) Spectral density samples for Asp 46 with values $5.2 \pm 0.6,3.2 \pm 0.1,0.22 \pm 0.04,0.10 \pm$ 0.5 , and $0.48 \pm 0.1 \times 10^{-10} \mathrm{~s} / \mathrm{rad}$. The $\rho_{\mathrm{H}^{\mathrm{N}} \mathrm{H}^{i}}$ contribution to the amide proton spin-lattice relaxation rates $R_{\mathrm{H}}\left(\mathrm{H}_{z}^{\mathrm{N}}\right)$ were found to be $3.3 \pm 0.08$ and $2.4 \pm 0.1 \mathrm{~s}^{-1}$ and for Arg 51 and Asp 46, respectively. 
coefficient of all the samplings $\left(c_{i}=1 / 4 d\right)$, and therefore the uncertainties are the most amplified here.

Figures $4 \mathrm{a}$ and $4 \mathrm{~b}$ depict the five $J(\omega)$ values for Arg 51 and Asp 46, respectively. It is clear that Arg 51 has a $J(0)$ component significantly larger than that of Asp 46 . In particular, for Arg $51 J(0)=8.8 \pm 0.2 \times 10^{-10} \mathrm{~s} / \mathrm{rad}$, whereas $J(0)=5.2 \pm 0.6$ $\times 10^{-10} \mathrm{~s} / \mathrm{rad}$ for Asp 46. As seen in the plots, the difference between these $J(0)$ values well exceeds the size of the corresponding error bars. Additionally, Arg 51 has a discrepancy between the $J\left(\omega_{\mathrm{H}^{N}}+\omega_{\mathrm{N}}\right)$ and $J\left(\omega_{\mathrm{H}^{\mathrm{N}}}-\omega_{\mathrm{N}}\right)$ components larger than that of Asp 46. This reflects the slower cross-relaxation rate (smaller NOE enhancement) of Arg $51\left(0.086 \pm 0.002 \mathrm{~s}^{-1}\right)$ as compared to that of Asp $46(0.107 \pm 0.002$ $\mathrm{s}^{-1}$ ). Together, these observations accentuate the fact that a single Lorentzian spectral density is not sufficient to describe the motions for all of the ${ }^{15} \mathrm{~N}-{ }^{1} \mathrm{H}$ bonds. The fact that $J(0)$ is significantly larger for Arg 51 suggests that its ${ }^{15} \mathrm{~N}-{ }^{1} \mathrm{H}$ bond reorients on a characteristically slower time scale than that of the ${ }^{15} \mathrm{~N}-{ }^{1} \mathrm{H}$ bond of Asp 46. This is consistent with what is known about the structure of eglin c (46). Specifically, Arg 51 participates in a parallel $\beta$ sheet and therefore represents a ${ }^{15} \mathrm{~N}-{ }^{1} \mathrm{H}$ bond involved in a well-defined secondary structure. In contrast, Asp 46 is part of a surface-binding loop (residues 42-47) which adopts a rigid conformation only after eglin c binds to its target protease. It is therefore reasonable the its ${ }^{15} \mathrm{~N}-{ }^{1} \mathrm{H}$ bond experiences significantly more motion than that of Arg 51 for the present case of unbound eglin c. Thus, the approach of spectral density mapping is sensitive to different local dynamics within the protein molecule.

\section{CONCLUDING REMARKS}

In summary, we have described how the spectral density functions of individual $\mathrm{NH}^{\mathrm{N}}$ bonds in proteins can be evaluated at specific frequencies by purely experimental means. This is facilitated by taking advantage of the information contained in both one- and two-spin relaxation measurements. Although we have focused on the use of antiphase and longitudinal two-spin-order relaxation rates here, the zero- and twoquantum relaxation rates could be used as well. The essential requirement is measurement of a sufficient number of relaxation parameters that depend on the same samplings of the spectral density function. The method is an improvement over the current approaches to protein relaxation studies, which are incapable of evaluating the spectral densities in the absence of a motional model. We note from Figs. 4a and $4 \mathrm{~b}$ that spectral density mapping using ${ }^{13} \mathrm{C}$ relaxation might provide a better distribution of sampling points in the spectral density. In this case, selectively labeled ${ }^{13} \mathrm{C}$ sites would be preferable to avoid the aforementioned complications from ${ }^{13} \mathrm{C}-{ }^{13} \mathrm{C}$ couplings. We are currently investigating these possibilities.

We have applied the method of spectral density mapping to the protein eglin $\mathrm{c}$ and have illustrated the feasibility of the approach with examples of spectral density samplings for two $\mathrm{NH}^{\mathrm{N}}$ bonds belonging to Arg 51 and Asp 46. The results indicate that method is sensitive to differences in the internal dynamics of these bonds. A more detailed examination of the spectral density data, including a more elaborate error analysis, is in progress for all individual $\mathrm{NH}^{\mathrm{N}}$ bonds, so that we may address the motivating problem of characterizing the internal motions of these bonds. This work will be presented elsewhere. 


\section{ACKNOWLEDGMENTS}

We thank Dr. Dirk Heinz and Dr. Marcus Grütter, Ciba-Geigy, Basel, Switzerland, for the gift of $\left[{ }^{15} \mathrm{~N}\right]$ eglin c. We also thank V. Thanabal and S. G. Hyberts for useful discussions. This work was supported by NSF Grant DMB-9007878 and NIH Grant T32-GM08270-03 to J.P.

\section{REFERENCES}

1. (a) N. R. Nirmala AND G. WAGNeR, J. Am. Chem. Soc. 110, 7557 (1988); (b) N. R. Nirmala AND G. WAGNER, J. Magn. Reson. 82, 659 ( 1989).

2. M. J. Dellwo and A. J. Wand, J. Am. Chem. Soc. 111, 4571 (1989).

3. L. E. KAY, D. A. TORCHIA, AND A. BAX, Biochemistry 28, 8972 (1989).

4. (a) G. M. Clore, P. C. Driscoll, P. T. Wingfield, And A. M. Gronenborn, Biochemistry 29 , 7387 (1990); (b) G. M. Clore, A. SzaBo, A. BAX, L. E. KaY, P. C. Driscoll, ANd A. M. GroNENBORN, J. Am. Chem. Soc. 112, 4989 (1990).

5. A. G. Palmer, III, M. RanCE, AND P. E. WRight, J. Am. Chem. Soc. 113, 4371 (1991).

6. D. E. WoEsSner, J. Chem. Phys. 36, 1 (1962).

7. K. Kinoshit八, S. K^WATO, JR., AND A. IKEGAMI, Biophys. J. 20, 289 (1977).

8. R. RichaRZ, K. NAGAYAMA, AND K. WÜTHRICH, Biochemistry 19, 5189 (1980).

9. (a) G. Lipari And A. Szabo, J. Am. Chem. Soc. 104, 4546 (1982); (b) G. Lipari ANd A. Szabo, $J$. Am. Chem. Soc: 104, 4559 (1982).

10. A. AbraGam, "The Principles of Nuclear Magnetism," Chap. 8, Clarendon Press, Oxford, 1961.

11. R. R. ERnst, G. Bodenhausen, A. Wok aun, "Principles of Nuclear Magnetic Resonance in One and Two Dimensions," pp. 50-57, 182, Clarendon Press, Oxford, 1987.

12. M. GoldmaN, "Quantum Description of High-Resolution NMR in Liquids," Chap. 9, Clarendon Press, Oxford, 1988.

13. A. D. Bain and R. M. Lynden-Bell, Mol. Phys. 2, 325 (1975).

14. I. G. Werbelow and D. M. Grant, in “Advances in Magnetic Resonance" (J. S. Waugh, Ed.), Vol. 9, p. 189, Academic Press, San Diego, 1977.

15. R. L. Vold AND R. R. Vold, Prog. NMR Spectrosc. 12, 79 (1978).

16. R. N. ZARE, "Angular Momentum," Chap. 2, Wiley, New York, 1988.

17. R. J. WITTEBORT AND A. SzABO, J. Chem. Phys. 69, 1723 (1978).

18. D. CANET, Prog. NMR Spectrosc. 21, 237 (1989).

19. M. GoldMan, J. Magn. Reson. 60, 437 (1984).

20. J. BoYd, U. Hommel, AND I. D. CaMPBell, Chem. Phys. Letl. 175, 477 (1990).

21. A. G. Palmer. III, N. J. Skelton, W. J. Chazin, P. E. Wright, and M. Rance, Mol. Phys., in press.

22. O. W. Sørensen, G. W. Eich, M. H. Levitt, G. Bodenhausen, ANd R. R. ERnst, Prog. NMR Spectrosc. 16, 163 (1983).

23. R. R. Vold AND R. L. Vold, J. Chem. Phys. 55, 1985 (1971).

24. R. E. London, J. Magn. Reson. 86, 410 (1990).

25. A. BAX, M. IkURA, L. E. KAY, D. A. TORChiA, ANd R. TSCHudin, J. Magn. Reson. 86, 304 (1990).

26. A. G. Palmer, III, J. Cavanagh, P. E. Wright, and M. Rance, J. Magn. Reson. 93, 151 (1991).

27. J. W. Peng, V. Thanabal, And G. Wagner, J. Magn. Reson. 95, 421 ( 1991 ).

28. G. Wagner, G. Bodenhausen, N. Müller, M. Rance, O. W. Sørensen, R. R. Ernst, and K. WUTHRICH, J. Am. Chem. SOC. 107, 6440 (1985).

29. A. Allerhand, D. Doddrell, and R. Komoroski, J. Chem. Phys. 55, 189 (1971).

30. I. Solomon, Phys. Rev. 99, 559 (1955).

31. G. P. Jones, Phys. Rev. 148, 332 (1966).

32. (a) J. S. BLICHARSKI, Acta Phys. Pol. A 41, 223 (1972); (b) Z. Naturforsch. A 27, 1355 (1972).

33. J. W. Peng, V. Thanabal, and G. Wagner, J. Magn. Reson. 94, 82 (1991).

34. Y. Hiyama, C. Niu, J. V. Silverton, A. Bavoso, and D. A. TorChia, J. Am. Chem. Soc. 110, 2378 (1988).

35. E. A. KeITER, Ph.D. Thesis, University of Illinois, 1986. 
36. G. A. Morris and R. Freeman, J. Am. Chem. Soc. 101, 760 (1979).

37. D. M. DodDRELl, D. T. PEGG, AND M. R. BENDALl, J. Magn. Reson. 48, 323 (1982).

38. D. Marion AND K. WUTHRICH, Biochem. Biophys. Res. Commun. 113, 967 (1983).

39. B. Messerle, G. Wider, G. Otting, C. Weber, ANd K. WÜthrich, J. Magn. Reson. 85, 608 (1989).

40. H. Y. CARr and E. M. Purcell, Phys. Rev. 94, 630 (1954).

41. S. MeiboOm AND D. Gill, Rev. Sci. Instrum. 29, 688 (1958).

42. C. Deverell, R. E. Morgan, and J. H. Strange, Mol. Phys. 18, 553 (1970).

43. G. WAGNER, Prog. NMR Spectrosc. 22, 101 (1990).

44. S. G. HYBERTS AND G. WAGNER, J. Magn. Reson. 81, 418 (1989).

45. D. W. MaRquaRdT, J. Soc. Ind. Appl. Math. 11, 431 (1963).

46. S. G. HYBERTS AND G. WAGNER, Biochemistry 29, 1465 (1990). 